\title{
Ultimate COVID-19 Detection Protocol Based on Saliva Sampling and qRT-PCR with Risk Probability Assessment
}

\author{
Joungha Won ${ }^{1,2}$, Hasan Hüseyin Kazan ${ }^{3}$, Jea Kwon ${ }^{2,4}$, Myungsun Park ${ }^{2}$, Mehmet Ali Ergun ${ }^{5}$, \\ Sureyya Ozcan ${ }^{6}$, Byung Yoon $\mathrm{Choi}^{7}$, Won Do Heo ${ }^{1 *}$ and C. Justin Lee ${ }^{2 *}$ \\ ${ }^{1}$ Department of Biological Sciences, Korea Advanced Institute of Science and Technology, Daejeon 34141, ${ }^{2}$ Center for \\ Cognition and Sociality, Cognitive Glioscience Group, Institute for Basic Science, Daejeon 34126, Korea, ${ }^{3}$ Department of \\ Biological Sciences, Middle East Technical University, Ankara 06800, Turkey, ${ }^{4} \mathrm{KU}$-KIST Graduate School of Converging \\ Science and Technology, Korea University, Seoul 02841, Korea, ${ }^{5}$ Department of Medical Genetics, Gazi University Faculty of \\ Medicine, Ankara 06560, ${ }^{6}$ Department of Chemistry, Middle East Technical University, Ankara 06800, Turkey, ${ }^{7}$ Department \\ of Otorhinolaryngology, Seoul National University Bundang Hospital, Seongnam 13620, Korea
}

\begin{abstract}
In the era of COVID-19 outbreak, various efforts are undertaken to develop a quick, easy, inexpensive, and accurate way for diagnosis. Although many commercial diagnostic kits are available, detailed scientific evaluation is lacking, making the public vulnerable to fear of false-positive results. Moreover, current tissue sampling method from respiratory tract requires personal contact of medical staff with a potential asymptomatic SARSCOV-2 carrier and calls for safe and less invasive sampling method. Here, we have developed a convenient detection protocol for SARS-COV-2 based on a non-invasive saliva self-sampling method by extending our previous studies on development of a laboratory-safe and low-cost detection protocol based on qRT-PCR. We tested and compared various self-sampling methods of self-pharyngeal swab and self-saliva sampling from non-carrier volunteers. We found that the self-saliva sampling procedure gave expected negative results from all of the non-carrier volunteers within 2 hours, indicating cost-effectiveness, speed and reliability of the saliva-based method. For an automated assessment of the sampling quality and degree of positivity for COVID-19, we developed scalable formulae based on a logistic classification model using both cycle threshold and melting temperature from the qRT-PCR results. Our newly developed protocol will allow easy sampling and spatial-separation between patient and experimenter for guaranteed safety. Furthermore, our newly established risk assessment formula can be applied to a large-scale diagnosis in health institutions and agencies around the world.
\end{abstract}

Key words: Coronavirus, COVID-19, SARS-CoV-2, Saliva sampling, COVID-19 risk assessment

INTRODUCTION

COVID-19, which is caused by the 2019 novel coronavirus

Submitted December 29,2020, Revised January 5, 2021,

Accepted January 6, 2021

* To whom correspondence should be addressed.

Won Do Heo, TEL: 82-42-350-2642, FAX: 82-42-350-2610

e-mail:wondo@kaist.ac.kr

C. Justin Lee, TEL: 82-42-878-9150, FAX: 82-42-878-9151

e-mail:cjl@ibs.re.kr
SARS-CoV-2, has emerged from Wuhan, China in 2019. SARSCoV-2 belongs to the Coronaviridae RNA virus family that penetrates respiratory epithelial cells and causes fever, cough, myalgia or fatigue, other various symptoms, and even death [1]. More importantly, asymptomatic carriers of SARS-CoV-2 can be a silent source of uncontrolled infection [2]. It has been reported that the spike protein of SARS-CoV-2 has been mutated from SARS$\mathrm{CoV}-2$, and enabled it to increase the infectivity by contacting with respiratory epithelial cells [3]. WHO reports on October $10^{\text {th }}$, 2020, that over 3.6 million infections have been reported worldwide, with a mortality rate of three percent [4]. Although the rates
Copyright $\odot$ Experimental Neurobiology 2021 www.enjournal.org
This is an Open Access article distributed under the terms of the Creative Commons Attribution Non-Commercial License (http://creativecommons.org/licenses/by-nc/4.0) which permits unrestricted non-commercial use, distribution, and reproduction in any medium, provided the original work is properly cited. 
of mortality are very various, it has been generally reported that the elderly, the immune-suppressed and those with other diseases are highly susceptible to SARS-CoV-2 infection and more likely to die [5]. What is more alarming is the fact that there is no sign of slowing down. Instead, there is a repeating pattern in several countries of a secondary outbreak, after a period of rapid initial outbreak. Therefore, tremendous research efforts on developing disinfection strategies and treatments to fight against COVID-19 are being actively conducted.

Another way to fight against COVID-19 is to develop a safe, fast and easy diagnostic method which allows to quickly determine the epidemiological surveillance of SARS-CoV-2 and execute preventive measures. The most popular diagnostic protocol for COVID-19 involves a step-by-step procedure starting from collection of tissue sample from a subject, isolation and extraction of viral RNA, and detection of SARS-CoV-2 specific genes [6]. Although various novel sampling and detection methods have been described, the traditional way of tissue sampling from respiratory tract and real-time gene expression analysis are widely used for the detection of SARS-CoV-2 in clinical settings [7]. There are two ways of tissue sampling from the upper respiratory tract: one from nasopharynx and the other from posterior oropharynx. Sampling through a nasal swab requires a deep insertion of a swab to nasopharynx inside the nose [8], which is a burdensome and uncomfortable process for the subject. Sampling from pharyngeal wall with a throat swab requires a step to press the tongue and scrape the tissue from the throat wall [9]. Even though a throat swab might be easier than a nasal swab, both methods should be performed by highly trained medical personnel. This requirement forces medical personnel to be constantly exposed to the infectious viruses. In fact, there have been numerous cases where medical personnel performing the tissue sampling inadvertently contracted COVID-19 [10]. In particular, a touching of the pharyngeal area could trigger pharyngeal reflex, resulting in nausea or cough from the subject and potentially increase the risk of transmitting the virus to nearby health care workers [10]. In fact, a risk of COVID-19 infection of the front-line health-care workers in the USA and the United Kingdom are ten times higher than normal population [11].

To protect medical staff from the danger of potential infection, we should be making additional efforts such as expanding noncontact health care, strengthening the protective gear for medical staff, and implementing self-tissue sampling method [11]. As a candidate self-tissue sampling, a saliva-based sampling has been previously used in the detection of Zika virus to ensure safe spatial separation between patient and medical staff and experimenters [6, $12,13]$. It has been already reported that SARS-CoV-2 virus can be detected in saliva as well as in the respiratory tract in COVID-19 patients [14], and the detection sensitivity during the time course of disease progression is similar between saliva and nasophyrngeal swab samples [15-17]. Given that pharyngeal swab is a widely used method in clinics [7], we consider that saliva-sampling is equally practical to detect SARS-CoV-2 virus during the time course of disease progression. These raise a hope for a complete spatial separation of a subject and medical staff via self-saliva sampling.

In addition to the problem of accidental exposure to SARS$\mathrm{CoV}-2$ in the clinics, frequent false-positive results during the diagnosis remain as a serious challenge. Most of the popular diagnostic kits utilize DNA-amplification of SARS-CoV-2 genes by Real-Time Quantitative Reverse Transcription Polymerase Chain Reaction (qRT-PCR) to determine the presence or absence of SARS-CoV-2 genes or positive or negative infection for COVID-19 [6]. During a conventional diagnosis, an experimenter obtains the result of qRT-PCR reaction for each sample in the form of the value for the threshold cycle (CT value) of an amplification plot. A well-known pitfall of qRT-PCR method is that it can give a non-specific amplification product due to a primer-dimerization, leading to a false-positive result [9]. We have previously described in detail the primer-design guidelines to prevent non-specific amplification and false-positive reactions and reported ten validated primer sets for SARS-CoV-2 detection in SYBR-green based qRTPCR and conventional PCR $[9,18]$. However, even with highly optimized primer sets, qRT-PCR reactions can often lead to an inadvertent amplification due to unknown thermal reactions or random formation of a primer-dimer. To circumvent this issue, we have previously proposed to take advantage of the melting temperature, Tm value, which is calculated from each qRT-PCR reaction [18]. Tm value for qRT-PCR reaction due to primer-dimerization should be different from the one due to a well-targeted reaction. An experimenter can evaluate in combination with CT and Tm values to determine the presence or absence of SARS-CoV-2 genes more accurately. Nevertheless, this process of evaluation is prone to errors arising from subjective opinions and personal biases of the experimenter. Therefore, there is a pressing need for developing an error-free and objective algorithm or formula composed of CT and Tm values to calculate the degree of the positivity or presence of SARS-CoV-2. Such algorithm or formula should be indispensable for large-scale testing facilities.

In a series of two previous papers, we have reported the laboratory-safe and low-cost SARS-CoV-2 detection protocol, which is composed of self-pharyngeal swab sampling procedure, a Trizolbased RNA extraction, cDNA reverse transcription, SYBR greenbased qRT-PCR protocol or conventional PCR, and optimized primer sets for SARS-CoV-2 detection $[9,18]$. In the current study, 
we set out to further develop and optimize a saliva-based ultimate detection protocol, equipped with scalable formulae based on logistic classification model.

\section{MATERIALS AND METHODS}

\section{Volunteer recruitment}

The purpose of the sampling and procedure through a pharyngeal swab and saliva-based sampling from volunteers were approved by Seoul National University Hospital Institutional Review Board (IRBY-H-1807-197-966) and IRB guidance lines. Total of 7 volunteers (Volunteer A-G) participated in this experiment. Some of these volunteers have direct or indirectly contact with SARSCoV-2 infected patients or visited a known COVID-19 outbreak area.

The saliva from two human subjects whom had been diagnosed as "COVID-19-positive subject" and "COVID-19-negative subject" in the Department of Medical Microbiology, Gazi University, Ankara, Turkey by a commercial TaqMan probe-based kit approved by Republic of Turkey Ministry of Health was also included in the study. The involvement of COVID-19-positive patient and -negative individual was allowed by Gazi University Clinical Research Comittee 13.10.2020/678 and the self-saliva sampling was performed after obtaining signed consent form from the patient and the individual.

\section{Self-pharyngeal swab and self-saliva sampling procedure}

Sampling was conducted strictly through self-collection procedure. Detailed procedure of self-pharyngeal swab is described in the previously published paper [9]. The saliva-based sampling procedure was modified from the previously described procedure [13]. Briefly, we asked volunteers to drool and spit at least $1 \mathrm{ml}$ saliva into sterile polypropylene medical container (Medical container, Catalog \#:400025, SPL, Republic of Korea), after brushing the teeth and vigorously rinsing the mouth with tap water. And then we added $20 \mu \mathrm{g}$ of Proteinase K solution (Proteinase K solution, $20 \mathrm{mg} / \mathrm{ml}$, Catalog \#:21560025-2, Bio-world, USA) for an inactivation of SARS-CoV-2. To further ensure an elimination of viral activity, we transferred $500 \mu \mathrm{l}$ of saliva and Proteinase $\mathrm{K}$ sample into $500 \mu \mathrm{l}$ Trizol (TRIzol ${ }^{\mathrm{TM}}$ Reagent, Catalog \#: 15596026, Invitrogen $^{\mathrm{TM}}$, USA), followed by mixing with pipetting vigorously up-and-down.

\section{Total RNA extraction}

Detailed procedure for Trizol-based manual RNA extraction is described in previously published paper [18]. Briefly, each sample was incubated in Trizol for 5 minutes in room temperature, and then $200 \mu$ chloroform was added, mixing by inverting the tube 5 times, incubated for 3 minutes and centrifuged for 15 minutes at $12,000 \times \mathrm{g}$ at $4{ }^{\circ} \mathrm{C}$. The clear upper aqueous layer which contained RNA was transferred to a new $1.5 \mathrm{ml}$ tube and same volume of isopropanol was added. After incubating for 10 minutes on room temperature, gently mix by inverting 5 times was followed. The sample was centrifuged for 10 minutes at $12,000 \times \mathrm{g}$ at $4{ }^{\circ} \mathrm{C}$. The supernatant was discarded and the remaining pellet was washed by $1 \mathrm{ml}$ of $70 \%$ ethanol and centrifuged for 10 minutes at $7,500 \times \mathrm{g}$ at $4^{\circ} \mathrm{C}$. The sample was washed again with $70 \%$ ethanol and centrifuged for 10 minutes at $7,500 \times \mathrm{g}$ at $4{ }^{\circ} \mathrm{C}$. The supernatant was discarded and the RNA pellet was air-dried for 5 minutes. To solubilize the RNA pellet, the pellet was re-suspended in $10 \mu \mathrm{l}$ of RNase-free water.

For the RNA kit preparation, we used QIAamp ${ }^{\circledR}$ Viral RNA Mini (Catalog \#: 52904, Qiagen, Germany) and modify the given protocol which is provided by the company. Each sample was incubated in Trizol for 5 minutes in room temperature, and then transferred to QIAamp Mini column and centrifuged at 6,000×g for 1 minute in room temperature. Then, we added $500 \mu \mathrm{l}$ AW 1 Buffer to the column and centrifuged at $6,000 \times \mathrm{g}$ for 1 minute in room temperature. And then, we added $500 \mu \mathrm{l}$ AW2 Buffer to the column and centrifuged at $20,000 \times \mathrm{g}$ for 3 minutes in room temperature. Finally, we eluted with $20 \mu \mathrm{l}$ of RNase-free water in a clean $1.5 \mathrm{ml}$ microcentrifuge tube.

\section{SARS-CoV-2 RNA as a positive control}

The positive control containing SARS-CoV-2 viral RNAs was obtained from the Korea Centers for Disease Control and Prevention (http://www.cdc.go.kr/). Detailed description of how SARSCoV-2 viral RNA was prepared in a separate report [19]. Briefly, SARS-CoV-2 viral RNA was prepared by extracting total RNA from Vero cell line, which is originated from the kidney of African green monkey (Cercopithecus aethiops), infected with a viral clone, BetaCoV/Korea/KCDC03/2020 at MOI 0.05.

\section{Reverse-transcription}

Extracted total RNA was converted to complementary DNA (cDNA) using SuperScript ${ }^{\mathrm{TM}}$ III First-Strand Synthesis System (Catalog \#: 18080051; Invitrogen ${ }^{\mathrm{TM}}$, USA), following the manufacturer's recommended procedures with some modifications. Detailed procedure of reverse transcription is described in previously published paper [9].

\section{Real-time qPCR}

2X Power SYBR ${ }^{\circledR}$ Green PCR Master Mix (Catalog \#: 4368577, Thermo Fisher Scientific, USA) was used. The thermal cycle con- 
ditions were $50^{\circ} \mathrm{C}$ for 2 minutes, $95^{\circ} \mathrm{C}$ for 10 minutes, 40 cycles with $95^{\circ} \mathrm{C}$ for 15 second and $62^{\circ} \mathrm{C}$ for 1 minute, followed by melting curve stage at $95^{\circ} \mathrm{C}$ for 10 second and $60^{\circ} \mathrm{C}$ for 1 minutes in Quantstudio 1 Real-Time PCR system (Applied Biosystems, USA) and CFX96 ${ }^{\mathrm{TM}}$ Real-Time PCR Detection System (Bio-Rad Laboratories, USA). Previously reported primer sets for SARS-CoV-2 detection and internal positive control are used [18]; SARSCoV-2_IBS_E2, SARS-CoV-2_IBS_RdRP2, SARS-CoV-2_IBS_ S2, SARS-CoV-2_IBS_N1, GAPDH primer sets. The final concentration of the primer mix was $500 \mathrm{nM}$.

\section{1-step real-time qPCR}

One Step TB Green ${ }^{\circledR}$ PrimeScript ${ }^{\mathrm{TM}}$ RT-PCR Kit (Catalog \#: RR066A, Takara, Japan) was used. We followed the manufacture's manual for preparing PCR mixture and thermal cycle conditions. In $20 \mu$ total reaction, we used $2 X$ One Step TB Green RT-PCR Buffer III $10 \mu \mathrm{l}$, TaKaRa Ex Taq HS 0.4 $\mu$ l, PrimeScript RT enzyme Mix II $0.4 \mu \mathrm{l}$, PCR Forward/Reverse Primer $(10 \mu \mathrm{M}) 0.4 \mu \mathrm{l}$, each, ROX Reference Dye or Dye II (50 X) $0.4 \mu$, total RNA $2 \mu \mathrm{l}$, and RNase free waater $6 \mu$. Thermal cycle was $42^{\circ} \mathrm{C}$ for 5 minutes, $95^{\circ} \mathrm{C}$ for 10 seconds, 40 cycles with $95^{\circ} \mathrm{C}$ for 5 second and $62^{\circ} \mathrm{C}$ for

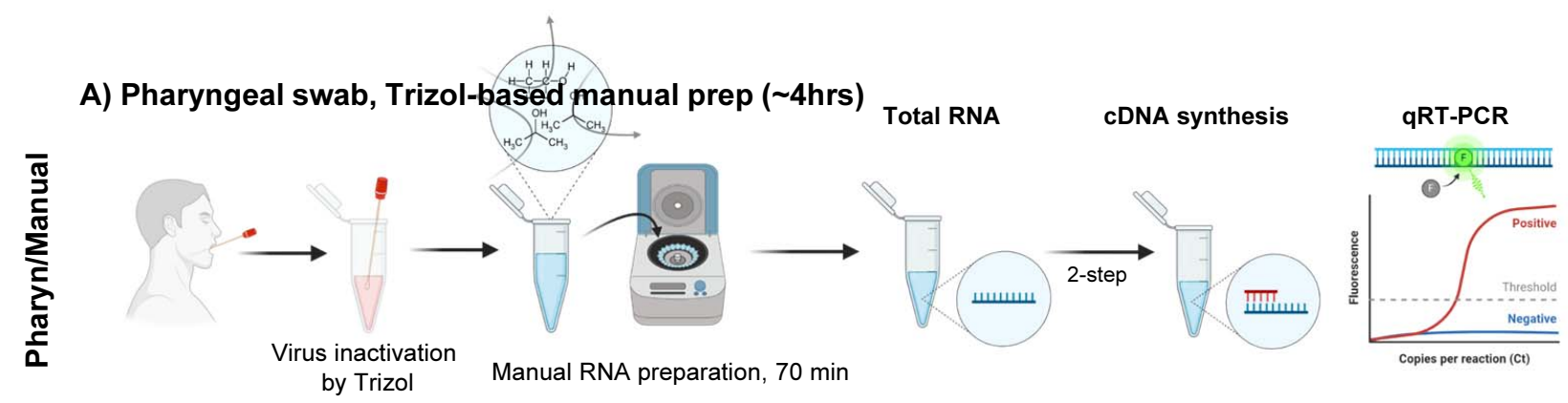

B) Pharyngeal swab, Trizol-based kit prep. ( 3.3hrs)

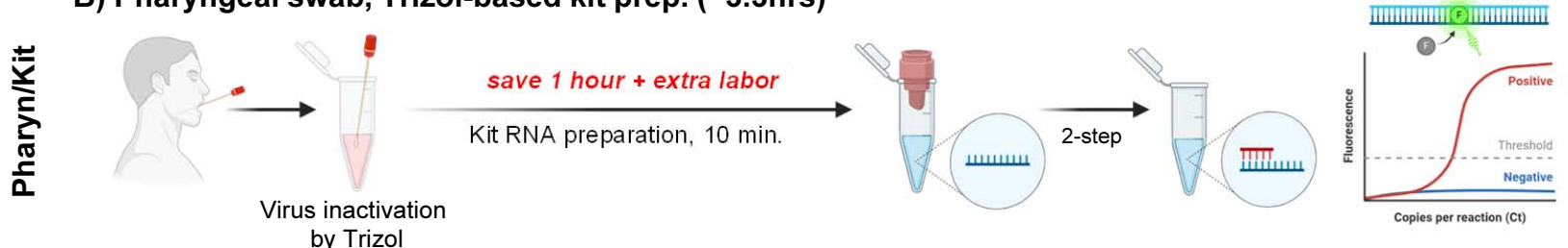
by Trizol

C) Saliva sample, Trizol-based kit prep, 2-step qRT-PCR ( 3.3hrs)
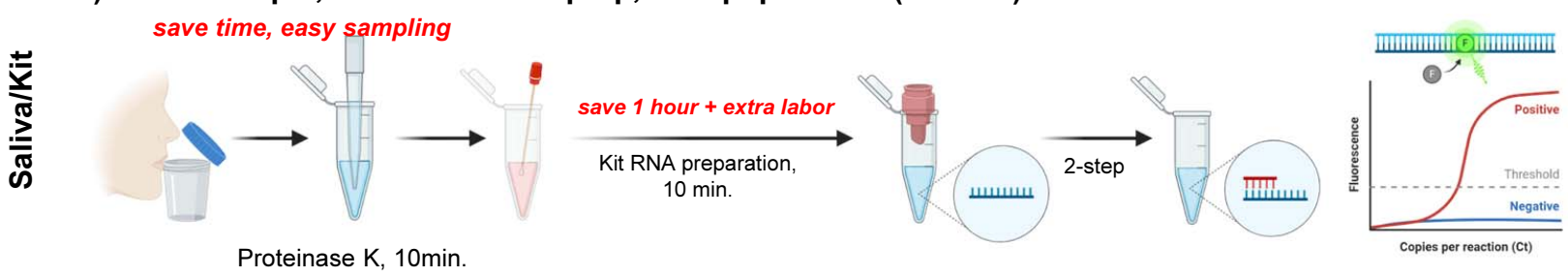

D) Saliva sample, Trizol-based kit prep, 1-step qRT-PCR (2hrs)
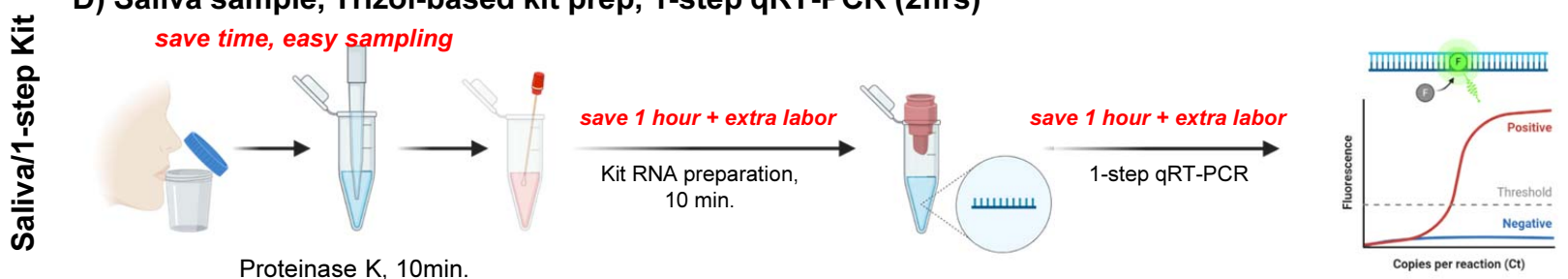

Fig. 1. Experimental scheme for safe, fast and easy human tissue sampling, total RNA extraction and qRT-PCR. (A and B) Samples are collected by selfpharyngeal swab and RNA are extracted by (A) Trizol-based manual RNA extraction method (Pharyn/Manual) or (B) Trizol and commercial RNA extraction kit (Pharyn/Kit). Trizol is used for inactivating viral infection. (C and D) Samples are collected by self-saliva sampling and RNA are extracted by Trizol and commercial RNA extraction kit. Trizol and proteinase $\mathrm{K}$ is used for inactivating viral infection. (C) cDNA synthesis and qRT-PCR are separately performed from saliva sample (Saliva/Kit) (D) cDNA synthesis and qRT-PCR are combined in one reaction (Saliva/1-step kit). 
A

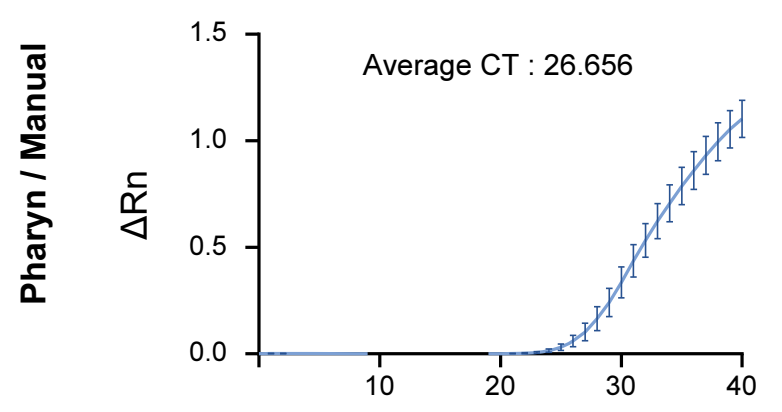

B

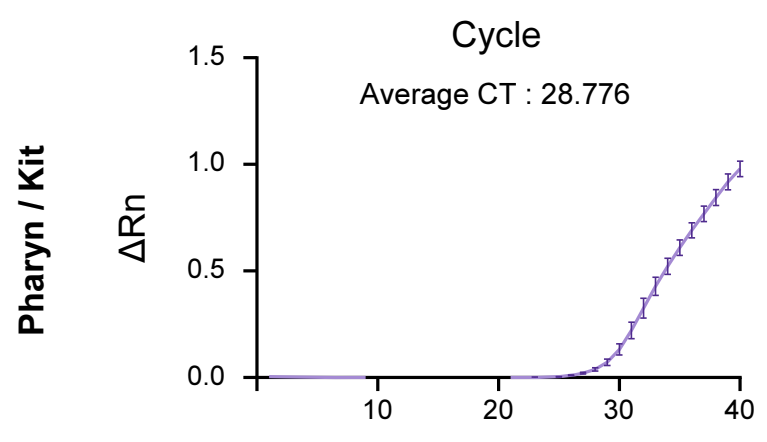

C
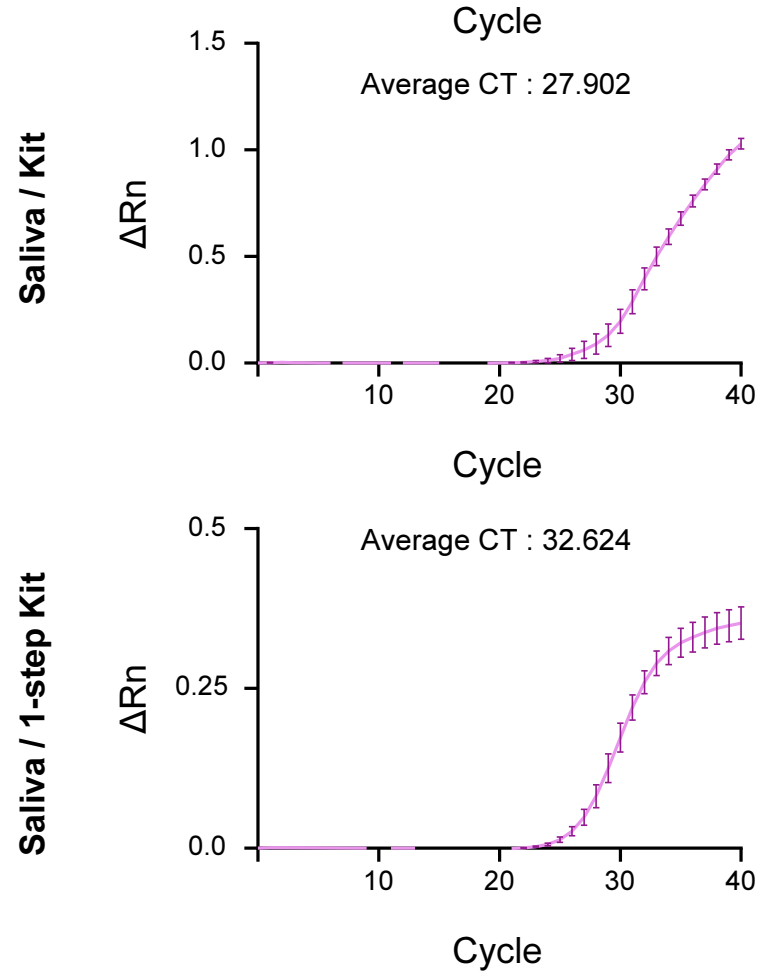

Melting curve plot

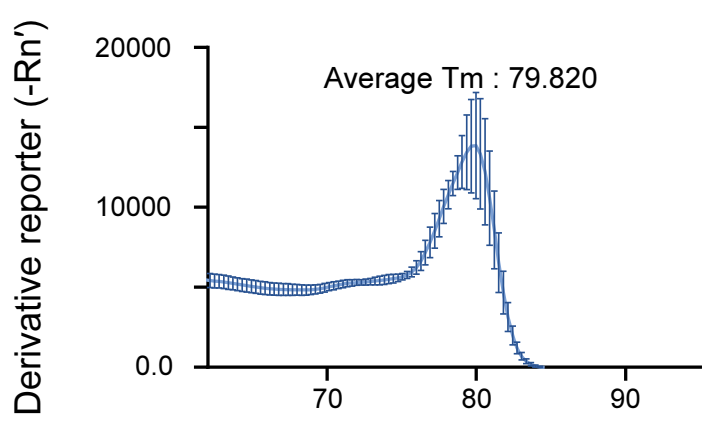

Temperature $\left({ }^{\circ} \mathrm{C}\right)$

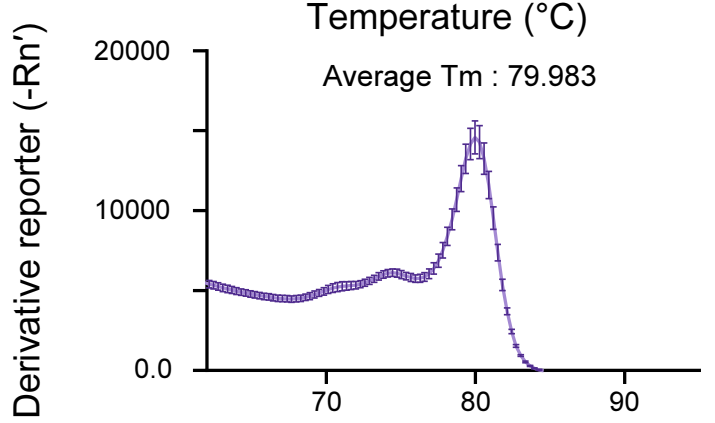

Temperature $\left({ }^{\circ} \mathrm{C}\right)$

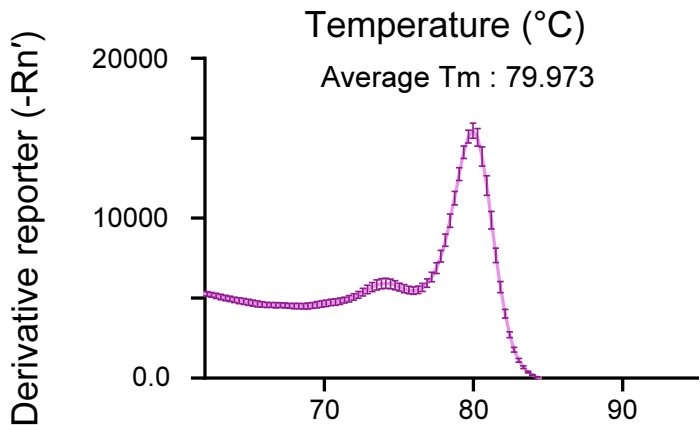

Temperature $\left({ }^{\circ} \mathrm{C}\right)$

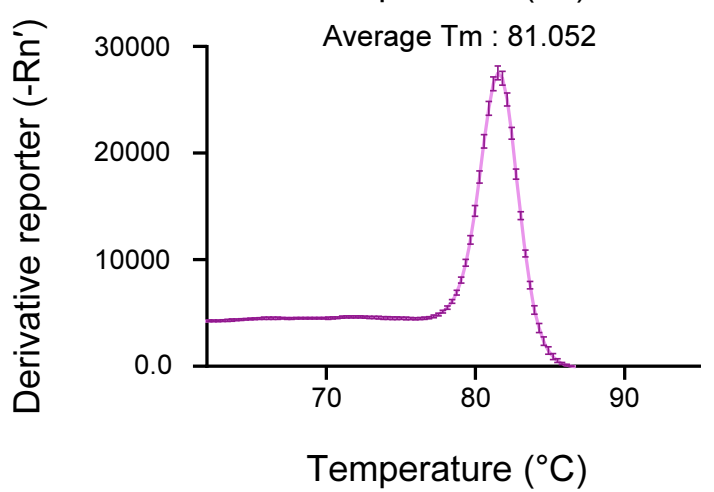

Fig. 2. Comparison of sampling quality between Pharyn/Manual, Pharyn/Kit, Saliva/Kit, and Saliva/1-step Kit by GAPDH qRT-PCR result. qRT-PCR result of amplification plot and melting curve plot from GAPDH primer set, from volunteer A-G, in (A) Pharyn/Manual, (B) Pharyn/Kit, (C) Saliva/ Kit and (D) Saliva/1-step Kit prep sample. Average CT value and average Tm value are described in each figures. Reporter value (Rn) is calculated by normalized the fluorescence signal from SYBR green to reference dye, ROX. Peaks in the melting curve plot represent the melting temperature [20] of amplicons. Derivative reporter (-Rn') was calculated as the negative first derivative of Rn generated by the reporter during PCR amplification. All data are represented as the mean \pm S.E.M. 


\section{E}

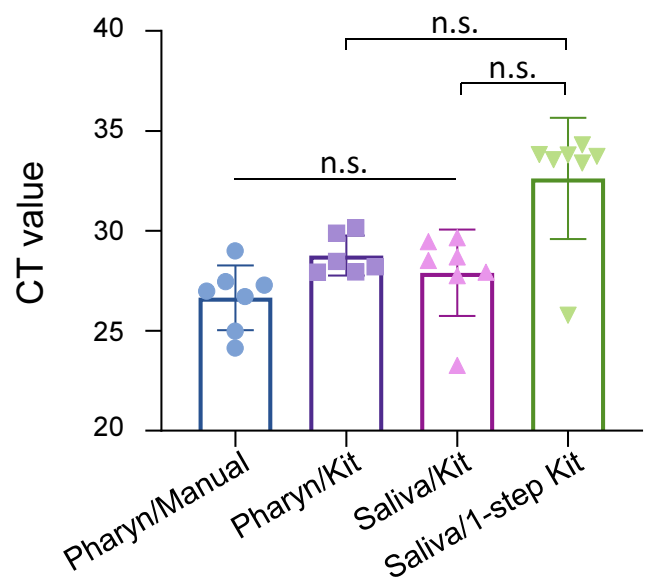

$\mathbf{F}$

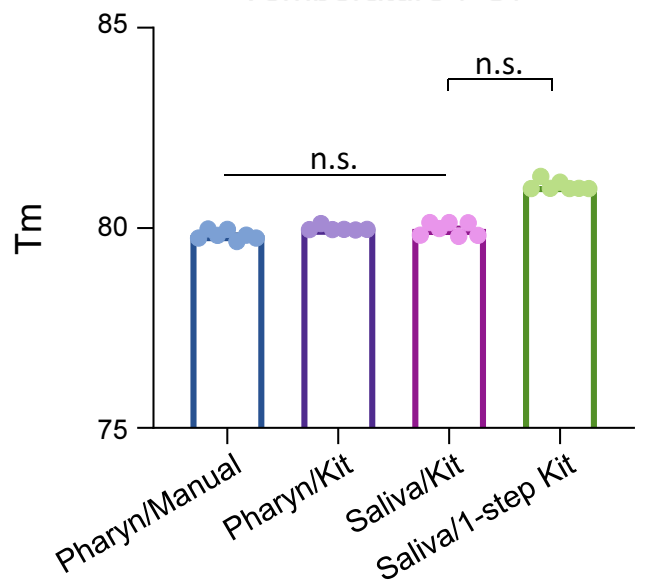

Fig. 2. Continued.

30 second. Other conditions were the same as described in Realtime qPCR.

\section{RESULTS}

\section{Self-tissue sampling protocols for SARS-CoV-2 detection}

To optimize the tissue sampling and RNA extraction procedure for enhanced safety, speed, and cost-effectiveness, we compared and contrasted four different procedures (Fig. 1A C); 1) Pharyn/ Manual: self-pharyngeal swab sampling and manual RNA preparation, 2) Pharyn/Kit: self-pharyngeal swab sampling and commercial kit-based 2-step RNA preparation, 3) Saliva/Kit: selfsaliva sampling and commercial kit-based 2-step cDNA reverse transcription and qRT-PCR, and 4) Saliva/1-step Kit: self-saliva sampling and 1-step qRT-PCR with combined cDNA reverse transcription and qRT-PCR. Pharyn/Manual procedure utilized a manual Trizol-based RNA extraction, whereas other procedures utilized Trizol-based RNA extraction kit. The difference between Saliva/Kit and Saliva/1-step Kit was that Saliva/1-step Kit utilized 1-step qRT-PCR with combined cDNA reverse transcription and qRT-PCR, whereas Saliva/Kit whereas Saliva/Kit utilized a 2-step procedure.

To assess the quality of tissue sampling, we performed qRT-PCR from 7 volunteers, who went through the two different tissue sampling methods and whose samples went through the four different procedures (Fig. 1A D). We found that Pharyn/Manual, Pharyn/ Kit, and Saliva/Kit sampling methods showed no significant difference in $\mathrm{CT}$ and $\mathrm{Tm}$ of amplicons in the human internal positive control, GAPDH (Fig. 2A C, 2E, 2F), indicating that the self-saliva sampling has similar sensitivity as the self-pharyngeal sampling. In addition, we found that Saliva/1-step Kit sampling showed slightly higher CT and Tm, compare to other procedures (Fig. 2D F). This might be caused by lower efficiency of the 1-step qRT-PCR kit, which has a shorter time of cDNA reverse transcription, shorter extension time in the thermal cycle, and lower primer concentration. Nevertheless, the CT and Tm values were within the positive range of GAPDH (Fig. 2E, 2F), indicating that the self-saliva sampling even with 1-step Kit has similar sensitivity as the selfpharyngeal sampling or the self-saliva sampling with 2-step RNA Kit.

To compare and contrast the cost-effectiveness and speed among the four procedures, we estimated the total cost per each sample (Table 1) and duration of each procedure (Table 2). We found that the manual RNA extraction method was the most economical ( \$15), although it took longer duration ( 4 hours) and more work load for the experimenter. Using the 2-step RNA prep kit slightly increased the cost, while reducing time to 3.3 hours and decreasing work load. Finally, with 1-step qRT-PCR kit and selfsaliva sampling, the entire procedure took less than 2 hours and under \$14 (Table 1 and Table 2), making the Saliva/1-step Kit the fastest and most cost-effective.

\section{Direct comparison of Pharyn/Manual, Pharyn/Kit, Saliva/ Kit, and Saliva/1-step Kit procedures}

Right after the local outbreak of COVID-19 infections near Gwanghwamun area in Seoul, Republic of Korea, on August 15 ${ }^{\text {th }}$, 2020, we performed the SARS-CoV-2 detection protocols for volunteers who have either unknowingly contacted SARS-CoV2-positive patient or visited near Gwanghwamun area during the outbreak. Tissue sampling was conducted only on asymptomatic volunteers, after proper self-quarantine, following the governmental or institutess guidelines. All volunteers had no symptoms related 
Table 1. Cost breakdown per volunteer sample

\begin{tabular}{lcccc}
\hline & Pharyn/Manual & Pharyn/Kit & Saliva/Kit & Saliva/1-step Kit \\
\hline Swab or collection tube and etc. & $\$ 0.50$ & $\$ 0.70$ & $\$ 0.70$ & $\$ 0.70$ \\
Trizol & $\$ 1.10$ & $\$ 1.10$ & $\$ 1.10$ & $\$ 1.10$ \\
RNA preperation kit & - & $\$ 7.70$ & $\$ 7.70$ & $\$ 7.70$ \\
Protease K & - & - & $\$ 1.50$ & $\$ 1.50$ \\
CDNA synthesis Kit & $\$ 8.13$ & $\$ 3.13$ & $\$ 3.13$ & \\
SYBR master mix & $\$ 3.25$ & & $\$ 1.25$ & $\$ 1.60$ \\
1-step-qRT-PCR kit & & $\$ 0.10$ & $\$ 10.10$ & $\$ 1.00$ \\
Primer set & $\$ 0.10$ & $\$ 1.00$ & $\$ 23.48$ & $\$ 13.70$ \\
Tubes and buffers & $\$ 2.50$ & $\$ 21.98$ & & \\
Total time & $\$ 15.58$ & & \\
\hline
\end{tabular}

Table 2. Durations of each sampling, RNA extraction and qRT-PCR procedure

\begin{tabular}{lcccc} 
& Pharyn/Manual & Pharyn/Kit & Saliva/Kit & Saliva/1-step Kit \\
\hline Self-pharyngeal swab collection & $\sim 10 \mathrm{~min}$ & $\sim 10 \mathrm{~min}$ & - & - \\
Self-saliva collection & - & - & $\sim 10 \mathrm{sec}$ & $\sim 10 \mathrm{sec}$ \\
RNA extraction & $\sim 70 \mathrm{~min}$ & $\sim 30 \mathrm{~min}$ & $\sim 40 \mathrm{~min}$ & $\sim 40 \mathrm{~min}$ \\
CDNA synthesis & $60 \mathrm{~min}$ & $60 \mathrm{~min}$ & $60 \mathrm{~min}$ & $5 \mathrm{~min}$ \\
qRT-PCR & $100 \mathrm{~min}$ & $100 \mathrm{~min}$ & $100 \mathrm{~min}$ & $65 \mathrm{~min}$ \\
Total time & $\sim 4 \mathrm{hrs}$ & $\sim 3.3 \mathrm{hrs}$ & $\sim 3.3 \mathrm{hrs}$ & $\sim 2 \mathrm{hrs}$ \\
\hline
\end{tabular}

to COVID-19.

To directly compare the efficiency and sensitivity of Pharyn/ Manual, Pharyn/Kit, Saliva/Kit, and Saliva/1-step Kit procedures, we firstly conducted self-tissue sampling and each diagnosis protocol for Volunteers A through G. We asked each volunteer to perform both self-pharyngeal swab sampling and self-saliva sampling. We then processed each sample through RNA extraction and qRT-PCR steps as depicted in Fig. 1A D. For the qRT-PCR, we utilized four SARS-CoV-2-targeted SARS-CoV-2_IBS_RdRP2, SARS-CoV-2_IBS_E2,SARS-CoV-2_IBS_S2,SARS-CoV-2_IBS_ $\mathrm{N} 1$, and one human gene-targeted GAPDH (for internal positive control) primer sets, which we have previously validated and reported $[9,18]$.

As expected, the SARS-CoV-2-targeting primer sets showed sufficient amplification in SARS-COV-2 positive control (the red traces in Fig. 3A D, Fig. 4A D, Fig. 5A D, and Fig. 6A D), and the GAPDH primer set showed sufficient amplification in all of the volunteer samples in all four procedures (Fig. 3E, Fig. 4E, Fig. 5E, and Fig. 6E). Among the four SARS-CoV-2-targeted primer sets, the S2-targeted primer set, SARS-CoV-2_IBS_S2, showed CT > 35 or undetermined (u.d.) in most of the volunteer samples (Fig. 3C and 3F; Fig. 4C and 4F; Fig. 5C and 5F; Fig. 6C and 6F), which can be interpreted as "negative" for SARS-CoV-2. This is based on the assumption that CT value of a single molecule (copy) amplification is near 35 [21]. In contrast, other SARS-CoV-2-targeted primer sets (SARS-CoV-2_IBS_RdRP2, SARS-CoV-2_IBS_E2, and
SARS-CoV-2_IBS_N1) sometimes showed CT $<35$ in some of the volunteer samples (Fig. 3 6; CT values in red), which could theoretically be interpreted as "positive" for SARS-CoV-2. However, Tm values for the corresponding melting curves showed a significant deviation of more than $0.3^{\circ} \mathrm{C}$ from the Tm value for SARS-CoV-2 positive control (Fig. 3 6; Tm values in red). In particular, Saliva/1step Kit procedure group showed the most number of $\mathrm{CT}<35$, which all turn out to be showing significant deviations of Tm from those of SARS-CoV-2 positive control (Fig. 6). These results indicate that the apparent $\mathrm{CT}<35$ in some of the samples might be caused by an inappropriate amplification due to primer-dimerization [18]. Thus, considering both CT and Tm values, all of the samples in all four procedures gave "negative" for SARS-CoV-2 as expected. These results imply that considering both CT and Tm is practical in eliminating false positives. Taken together, these results validate the sufficient efficiency and sensitivity of the protocols with both self-pharyngeal and self-saliva sampling, even with the time-saving 1-step qRT-PCR kit.

\section{Development of a mathematical formula for automatic determination of sampling quality and risk assessment based on logistic classification model}

We targeted and detected four different genes in SARS-CoV-2 for COVID-19 detection. As previously described [9], we considered subject as COVID-19-positive if at least one of the four different SARS-CoV-2 genes is positive. Therefore, we considered 


\section{Pharyn/Manual}

\section{Amplification plot}

A

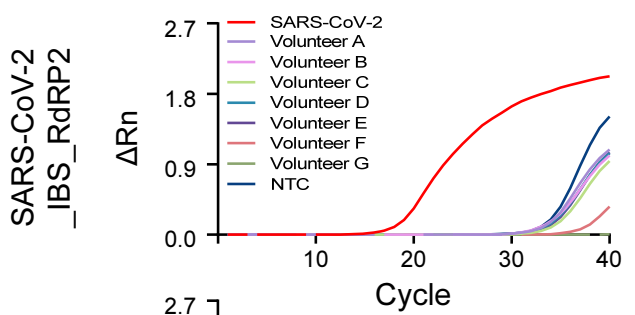

B

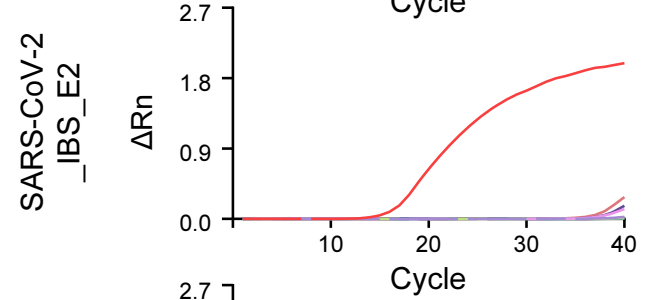

C

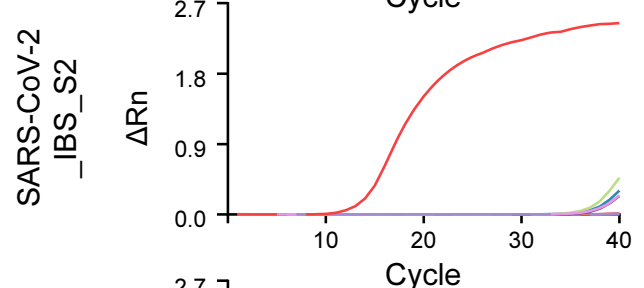

D

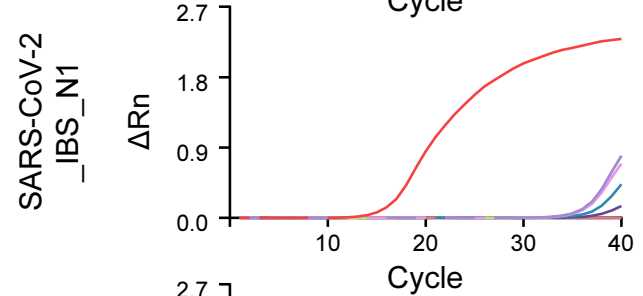

E

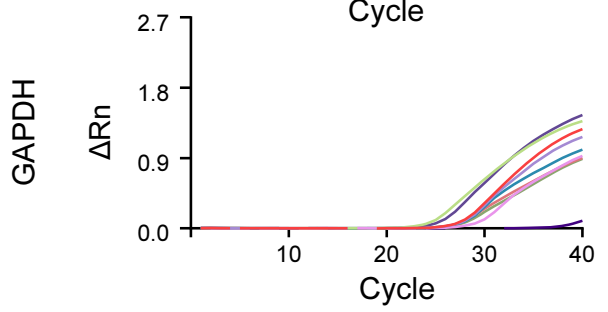

$\mathbf{F}$
Melting curve plot
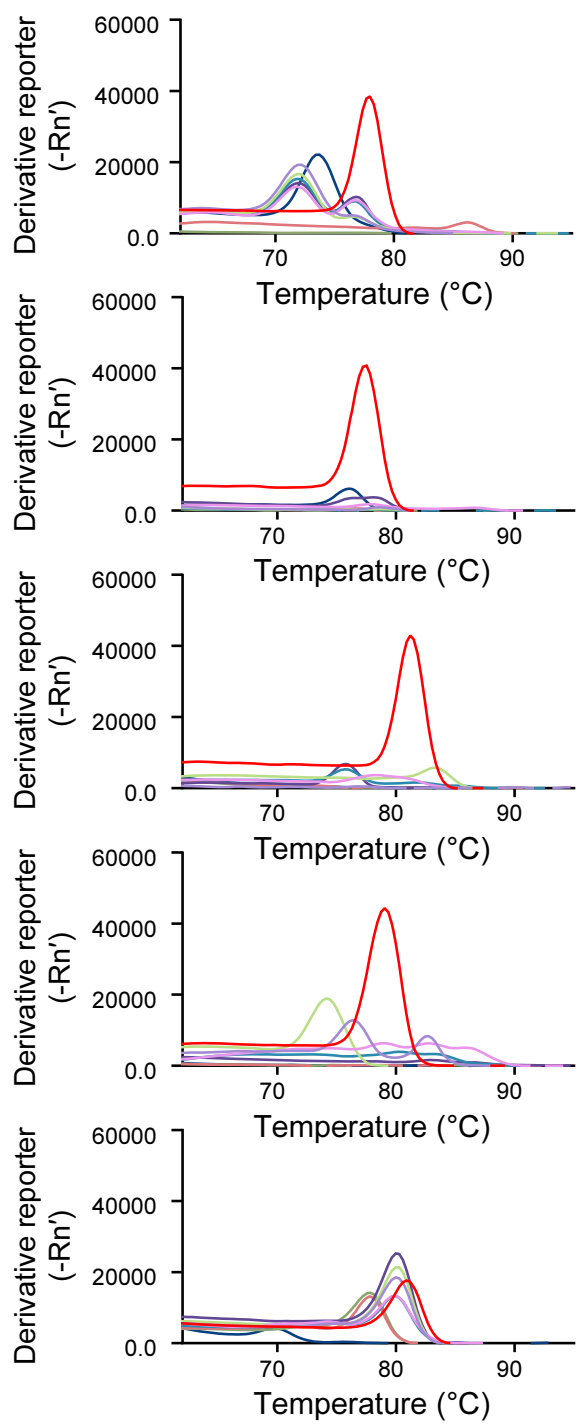

\begin{tabular}{|c|c|c|c|c|c|c|c|c|c|c|}
\hline & \multicolumn{10}{|c|}{ Pharyn/Manual } \\
\hline & \multicolumn{5}{|c|}{ CT value } & \multicolumn{5}{|c|}{$\operatorname{Tm}\left({ }^{\circ} \mathrm{C}\right)$} \\
\hline & RdRP2 & E2 & S2 & N1 & GAPDH & RdRP2 & E2 & S2 & N1 & GAPDH \\
\hline SARS-CoV-2 & 17.974 & 14.848 & 13.848 & 15.988 & 26.956 & 78.126 & 77.511 & 81.198 & 79.047 & 81.020 \\
\hline Volunteer A & 34.796 & u.d. & u.d. & 34.473 & 27.298 & 72.042 & 59.999 & 59.999 & 76.310 & 79.816 \\
\hline Volunteer B & 34.872 & 37.818 & 36.908 & 34.685 & 28.996 & 71.889 & 77.682 & 77.986 & 78.749 & 79.663 \\
\hline Volunteer C & 35.701 & u.d. & 35.913 & 34.573 & 24.145 & 76.767 & 59.999 & 83.017 & 74.023 & 79.968 \\
\hline Volunteer D & 35.033 & u.d. & 36.670 & 35.882 & 27.465 & 71.889 & 59.999 & 75.704 & 80.126 & 79.821 \\
\hline Volunteer $\mathrm{E}$ & 35.207 & 37.651 & 37.109 & 37.527 & 24.989 & 71.892 & 77.992 & 75.552 & 61.676 & 79.974 \\
\hline Volunteer $\mathrm{F}$ & 37.782 & u.d. & 36.653 & u.d. & 26.708 & 66.589 & 73.627 & 77.911 & 62.000 & 79.747 \\
\hline Volunteer G & u.d. & u.d. & u.d. & u.d. & 26.988 & 62.000 & 91.528 & 62.000 & 62.000 & 79.747 \\
\hline NTC & 37.735 & 37.712 & 36.470 & u.d. & u.d. & 75.616 & 93.517 & 62.000 & 62.000 & 71.638 \\
\hline
\end{tabular}

Fig. 3. Amplification and melting curve plot from Volunteer A G's Pharyn/Manual samples. Amplification plot (left panel) and melting curve plot (right panel) from qRT-PCR of volunteer A G's pharyn/manual samples. qRT-PCR was performed by using the previously reported SARS-CoV-2 primer sets; (A) SARS-CoV-2_IBS_RdRP2, (B) SARS-CoV-2_IBS_E2, (C) SARS-CoV-2_IBS_S2, (D) SARS-CoV-2_IBS_N1. (E) GAPDH primer set was used for IPC detection. Each color code represent individual volunteer result and SARS-CoV-2 amplification was represent as red color. (F) $\mathrm{Ct}$ value and Tm from volunteers A G’s Pharyn/Manual samples. 


\section{Pharyn/Kit}

Amplification plot

A

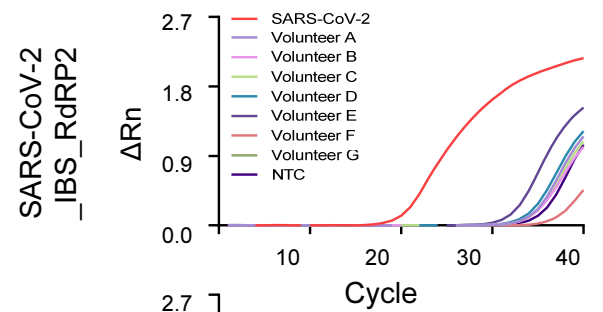

B

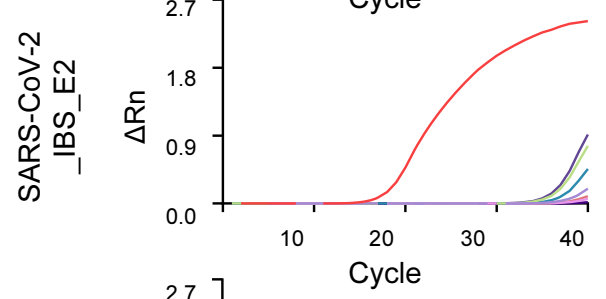

C

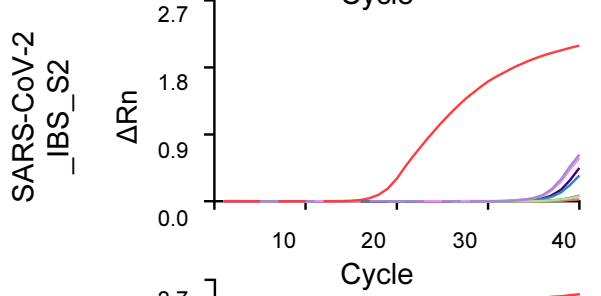

D
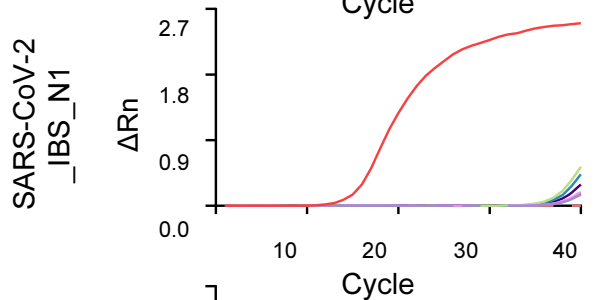

E

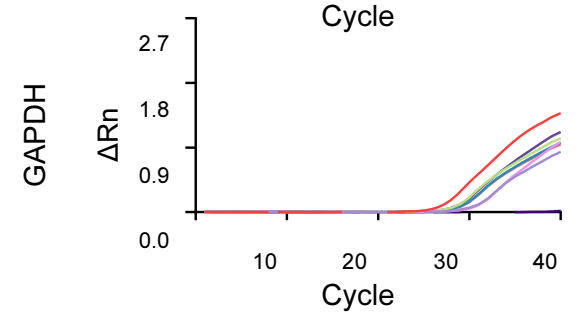

Melting curve plot
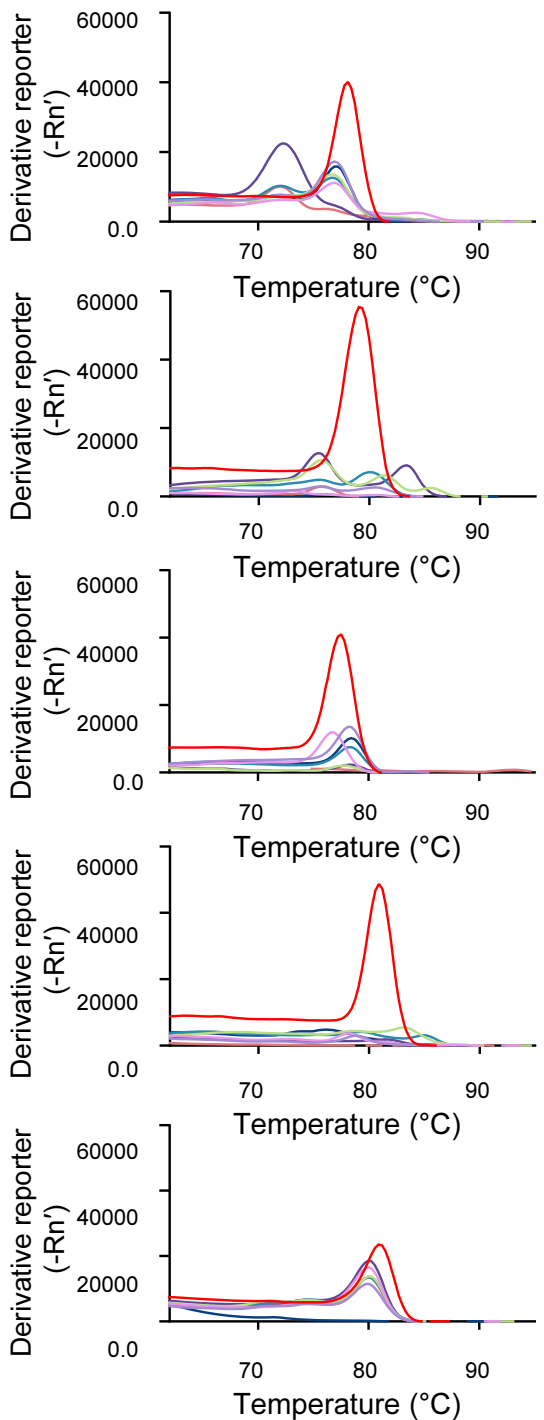

\section{$\mathbf{F}$}

\begin{tabular}{|c|c|c|c|c|c|c|c|c|c|c|}
\hline & \multicolumn{10}{|c|}{ Pharyn/Kit } \\
\hline & \multicolumn{5}{|c|}{ CT value } & \multicolumn{5}{|c|}{$\operatorname{Tm}\left({ }^{\circ} \mathrm{C}\right)$} \\
\hline & RdRP2 & E2 & S2 & N1 & GAPDH & RdRP2 & E2 & S2 & N1 & GAPDH \\
\hline SARS-CoV-2 & 20.938 & 16.943 & 16.138 & 13.124 & 26.267 & 78.112 & 77.498 & 79.187 & 80.875 & 81.029 \\
\hline Volunteer A & 35.057 & 34.905 & 37.240 & 37.671 & 29.882 & 76.884 & 78.266 & 75.503 & 78.880 & 79.954 \\
\hline Volunteer B & 35.263 & 35.003 & 39.160 & 37.389 & 30.152 & 65.832 & 76.731 & 73.200 & 78.112 & 79.954 \\
\hline Volunteer C & 35.226 & 38.920 & 34.697 & 35.507 & 27.926 & 76.731 & 77.805 & 75.656 & 83.178 & 80.108 \\
\hline Volunteer D & 34.610 & 36.393 & 35.872 & 36.010 & 28.484 & 65.529 & 78.277 & 80.120 & 65.376 & 79.967 \\
\hline Volunteer E & 32.740 & 38.726 & 34.351 & 37.547 & 27.952 & 71.980 & 78.431 & 75.359 & 81.503 & 79.967 \\
\hline Volunteer F & 36.174 & u.d. & 38.448 & u.d. & 28.201 & 71.967 & 59.999 & 75.803 & 59.999 & 79.946 \\
\hline Volunteer G & - & - & - & - & - & - & - & - & - & - \\
\hline NTC & 35.973 & 35.961 & u.d. & 36.620 & u.d. & 71.980 & 78.431 & 60.000 & 76.281 & 79.967 \\
\hline
\end{tabular}

Fig. 4. Amplification and melting curve plot from Volunteer A Gs' Pharyn/Kit samples. Amplification plot (left panel) and melting curve plot (right panel) from qRT-PCR of volunteer A G's pharyn/kit samples. qRT-PCR was performed by using the previously reported SARS-CoV-2 primer sets; (A) SARS-CoV-2_IBS_RdRP2, (B) SARS-CoV-2_IBS_E2, (C) SARS-CoV-2_IBS_S2, (D) SARS-CoV-2_IBS_N1. (E) GAPDH primer set was used for IPC detection. Each color code represent individual volunteer result and SARS-CoV-2 amplification was represent as red color. (F) $\mathrm{Ct}$ value and Tm from volunteers A G’s Pharyn/Kit samples. 


\section{Saliva/Kit}

Amplification plot

A

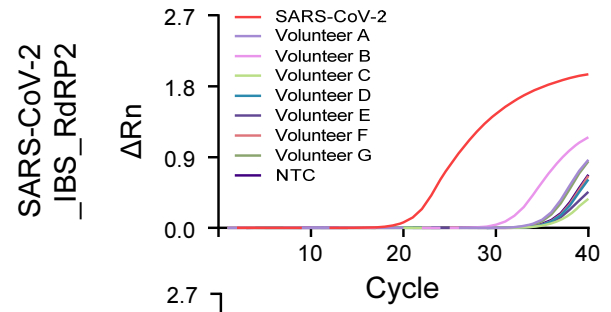

B

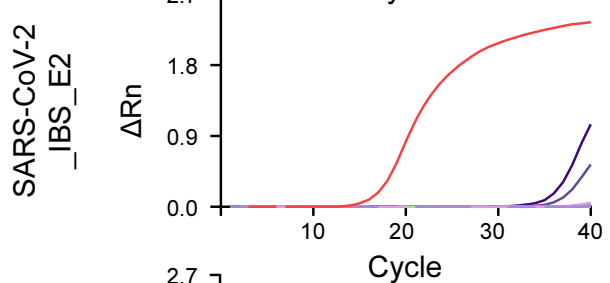

C

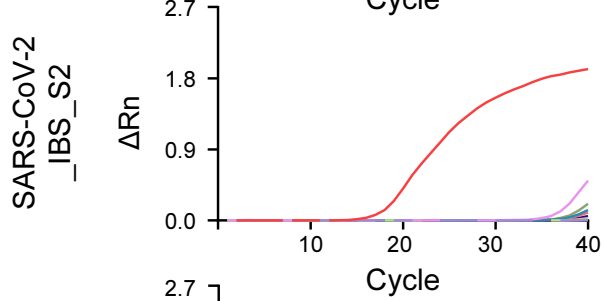

D

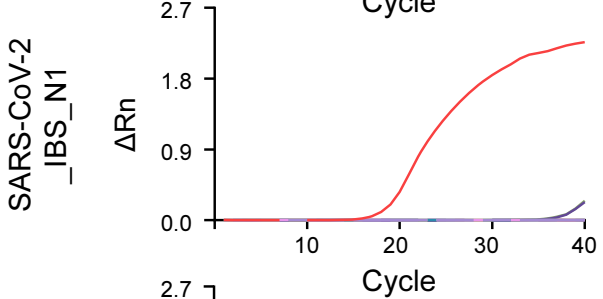

E

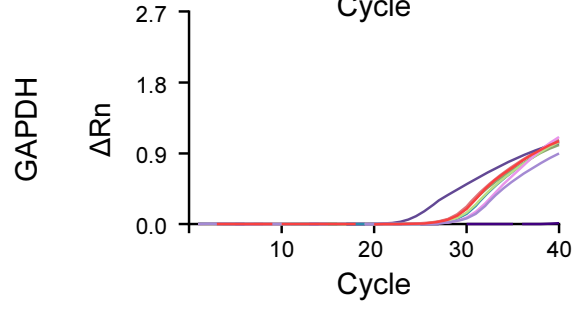

Melting curve plot
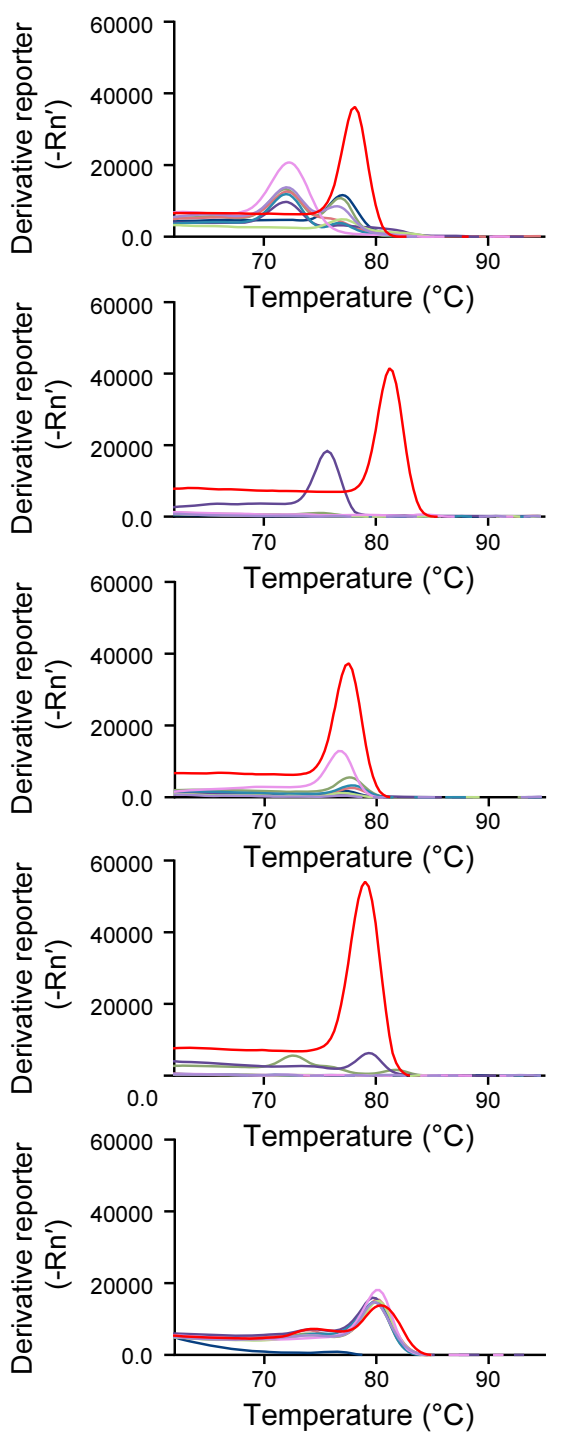

$\mathbf{F}$

\begin{tabular}{|c|c|c|c|c|c|c|c|c|c|c|}
\hline & \multicolumn{10}{|c|}{ Saliva/Kit } \\
\hline & \multicolumn{5}{|c|}{$C T$ value } & \multicolumn{5}{|c|}{$\operatorname{Tm}\left({ }^{\circ} \mathrm{C}\right)$} \\
\hline & RdRP2 & E2 & S2 & N1 & GAPDH & RdRP2 & E2 & S2 & N1 & GAPDH \\
\hline SARS-CoV-2 & 20.506 & 16.230 & 17.015 & 18.335 & 28.015 & 77.972 & 77.358 & 81.198 & 79.047 & 80.891 \\
\hline Volunteer A & 34.881 & u.d. & u.d. & u.d. & 29.664 & 71.981 & 59.999 & 59.999 & 60.614 & 79.815 \\
\hline Volunteer B & 31.225 & 35.507 & u.d. & u.d. & 29.456 & 72.288 & 76.743 & 73.056 & 59.999 & 80.123 \\
\hline Volunteer C & 36.880 & u.d. & u.d. & u.d. & 28.529 & 77.059 & 77.059 & 60.000 & 63.381 & 80.133 \\
\hline Volunteer D & 36.185 & 37.918 & u.d. & u.d. & 28.700 & 71.988 & 77.828 & 60.000 & 60.000 & 79.826 \\
\hline Volunteer E & 35.671 & u.d. & 35.541 & 37.132 & 23.274 & 71.967 & 62.147 & 75.650 & 79.332 & 79.792 \\
\hline Volunteer $\mathrm{F}$ & 36.095 & 38.313 & u.d. & u.d. & 27.762 & 72.141 & 77.828 & 60.000 & 60.000 & 80.133 \\
\hline Volunteer G & 35.111 & 37.290 & u.d. & u.d. & 27.928 & 71.992 & 77.680 & 59.999 & 60.000 & 79.986 \\
\hline NTC & 35.922 & 39.318 & 36.112 & u.d. & u.d. & 77.065 & 77.219 & 80.448 & 60.768 & 78.756 \\
\hline
\end{tabular}

Fig. 5. Amplification and melting curve plot from Volunteer A G's Saliva/Kit samples. Amplification plot (left panel) and melting curve plot (right panel) from qRT-PCR of volunteer A G's saliva/kit samples. qRT-PCR was performed by using the previously reported SARS-CoV-2 primer sets; (A) SARS-CoV-2_IBS_RdRP2, (B) SARS-CoV-2_IBS_E2, (C) SARS-CoV-2_IBS_S2, (D) SARS-CoV-2_IBS_N1. (E) GAPDH primer set was used for IPC detection. Each color code represent individual volunteer result and SARS-CoV-2 amplification was represent as red color. (F) Ct value and Tm from volunteers A G’s Saliva/Kit samples. 


\section{Saliva/1-step Kit}

Amplification plot

A

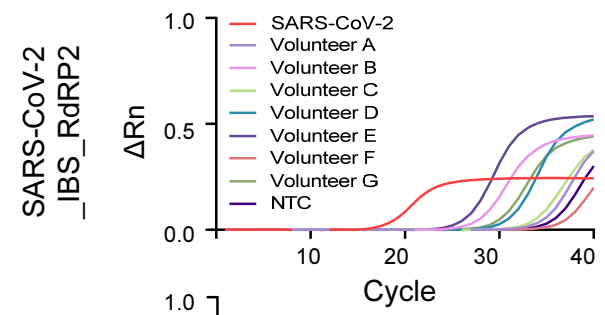

B

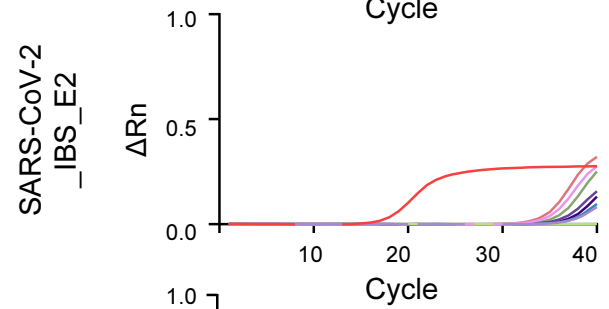

C

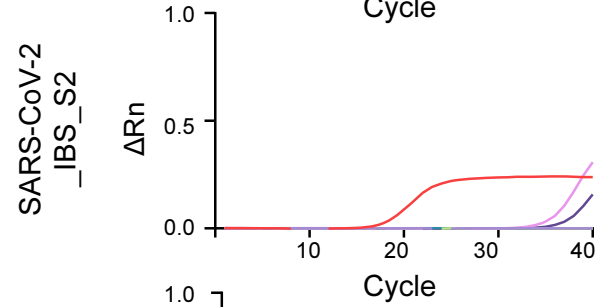

D

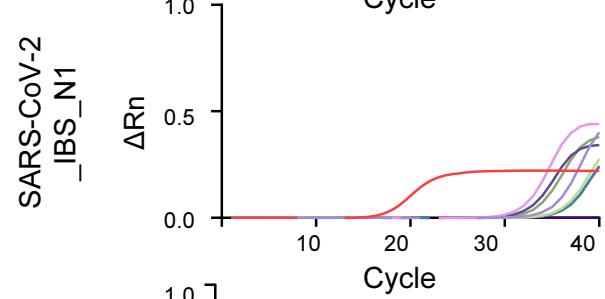

$\mathbf{F}$

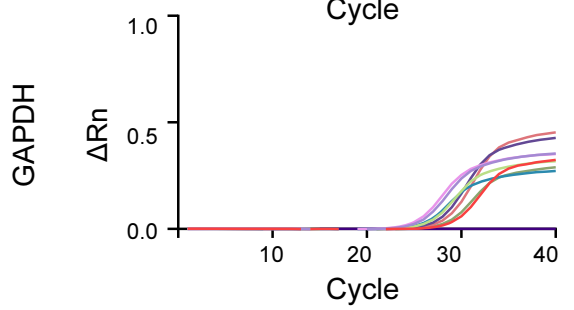

Melting curve plot
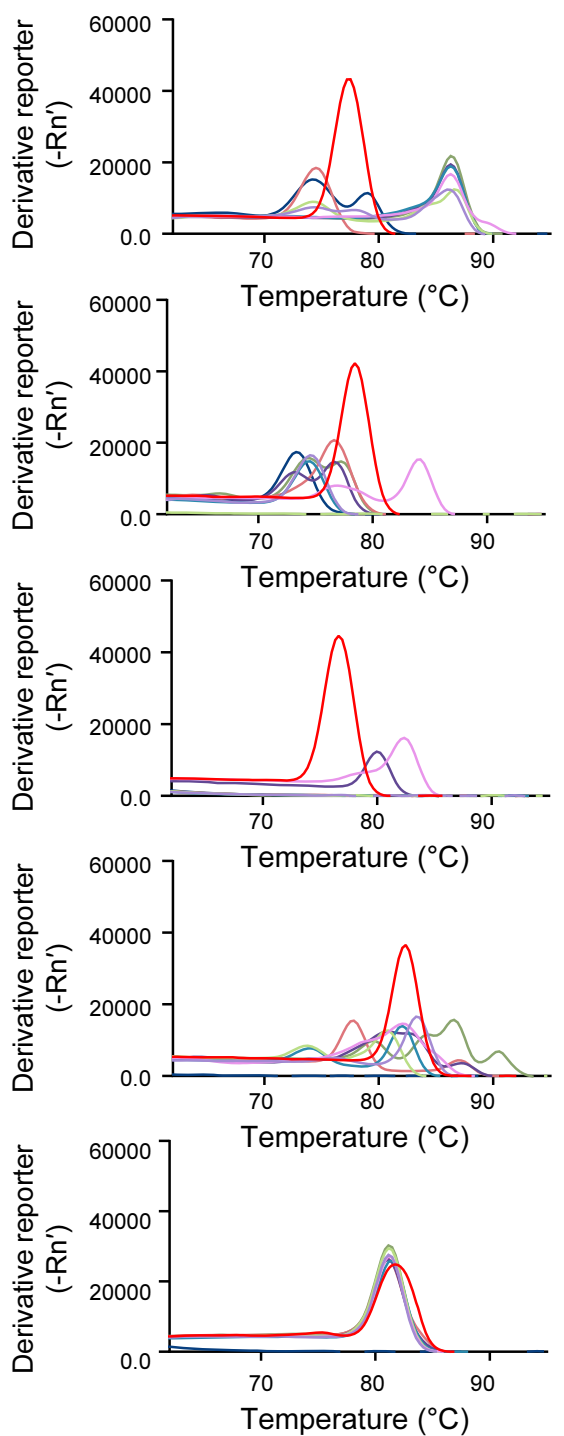

\begin{tabular}{|c|c|c|c|c|c|c|c|c|c|c|}
\hline & \multicolumn{10}{|c|}{ Saliva/1-step Kit } \\
\hline & \multicolumn{5}{|c|}{ CT value } & \multicolumn{5}{|c|}{$\operatorname{Tm}\left({ }^{\circ} \mathrm{C}\right)$} \\
\hline & RdRP2 & E2 & S2 & N1 & GAPDH & RdRP2 & E2 & S2 & N1 & GAPDH \\
\hline SARS-CoV-2 & 18.594 & 18.237 & 18.517 & 18.071 & 30.446 & 77.369 & 78.427 & 76.614 & 82.354 & 81.891 \\
\hline Volunteer $\mathbf{A}$ & 34.359 & 38.423 & u.d. & 34.614 & 34.309 & 86.130 & 74.651 & 60.000 & 83.411 & 80.985 \\
\hline Volunteer B & 37.538 & 34.994 & 35.355 & 34.614 & 25.293 & 86.281 & 84.015 & 82.354 & 78.871 & 80.985 \\
\hline Volunteer C & 33.470 & u.d. & u.d. & 35.885 & 33.793 & 86.734 & 61.510 & 60.000 & 80.692 & 80.985 \\
\hline Volunteer D & 30.587 & 38.171 & u.d. & 36.248 & 33.806 & 86.292 & 74.355 & 60.000 & 82.061 & 80.989 \\
\hline Volunteer $E$ & 27.620 & 37.177 & 37.053 & 33.797 & 33.554 & 86.292 & 76.621 & 79.945 & 80.852 & 81.001 \\
\hline Volunteer $\mathrm{F}$ & 36.769 & 34.373 & u.d. & 36.247 & 33.395 & 74.506 & 76.621 & 60.000 & 77.679 & 80.989 \\
\hline Volunteer G & 29.723 & 35.917 & u.d. & 33.036 & 33.719 & 86.292 & 74.355 & 60.000 & 86.594 & 81.140 \\
\hline NTC & 35.447 & 37.661 & u.d. & u.d. & u.d. & 75.555 & 78.274 & 59.999 & 78.123 & 59.999 \\
\hline
\end{tabular}

Fig. 6. Amplification and melting curve plot from Volunteer A G's Saliva/1-step Kit samples. Amplification plot (left panel) and melting curve plot (right panel) from qRT-PCR of volunteer A G’s saliva/1-step kit samples. To determine whether volunteers are infected to SARS-CoV-2, qRT-PCR was performed by using the previously reported SARS-CoV-2 primer sets; (A) SARS-CoV-2_IBS_RdRP2, (B) SARS-CoV-2_IBS_E2, (C) SARS-CoV-2_IBS_ S2, (D) SARS-CoV-2_IBS_N1. (E) GAPDH primer set was used for IPC detection. Each color code represent individual volunteer result and SARSCoV-2 amplification was represent as red color. (F) Ct value and Tm from volunteers A Gss Saliva/1-step Kit samples. 
Manual COVID-19 risk assessment

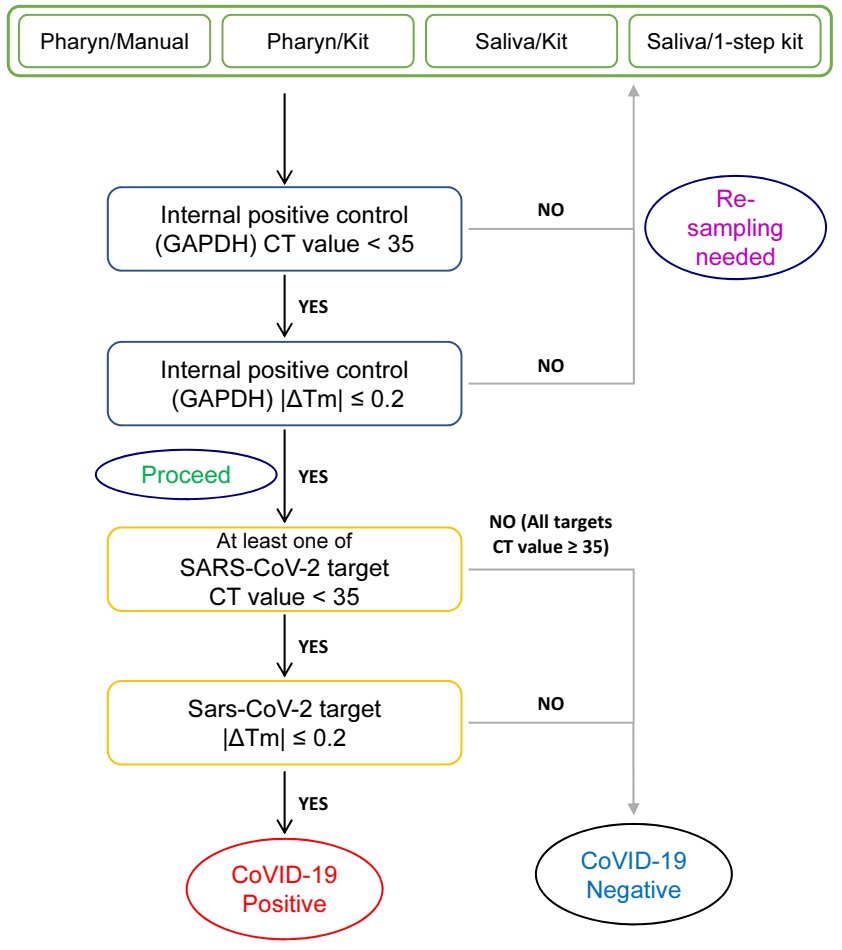

Fig. 7. Flow chart for manual SARS-CoV-2 risk assessment process.

subject as COVID-19-negative only when all four diffrent SARS$\mathrm{CoV}-2$ genes were negative. This approach was optimized for ensuring and distinguishing the true-negative infection from potential positives.

During the processes of tissue sampling, RNA preparation and qRT-PCR, we realized that the manual determination of "positive" or "negative" by an experimenter requires some aspect of personal judgement (Fig. 7), which could allow biases and errors to enter. Especially in the case of Saliva/1-step Kit with many reactions showing $\mathrm{CT}<35$ (Fig. 6), we identified multiple error-prone, decision-requiring steps (Fig. 7), in which personal biases and misjudgment could lead to false positives. To eliminate these possibilities, we set out to develop an error-free, unbiased mathematical formula to determine the "positive" or "negative" for SARS-CoV-2 based on the observed CT and Tm values.

For SARS-CoV-2 infection risk probability assessment and sampling quality assessment, we developed a formula for the probability $\sigma$, based on the logistic classification model [22]:

$$
\left.\sigma(x, a, b)=\frac{1}{1+\mathrm{e}^{\mathrm{a}(x-\mathrm{b})}} \quad \text { (Equation } 1\right)
$$

(note, $a$ : steepness, $b$ : threshold).

In this equation, the probability, $\sigma$ ranges from 0 to 1 , where 0 represents "no risk" and 1 "high risk". We developed a formula for CT value risk probability assessment $\left(\sigma_{\mathrm{CT}}\right)$, based on Equation 1. We assumed that CT value of a single molecule (copy) amplification is $\geq 35$ based on the previous work [21]. Thus, we setup the threshold value, $b=35$. We also adjusted the steepness value, $a$ to give probabilities of 0.05 at CT $35+1$ and 0.95 at CT 35-1. This estimation resulted in steepness value, $b=3$;

$$
\sigma_{C T}(\mathrm{CT}, 3,35)=\frac{1}{1+\mathrm{e}^{3(\mathrm{CT}-35)}} \quad(\text { Equation } 2) .
$$

The graphical representation of $\sigma_{\mathrm{CT}}$ is shown in Fig. 8A.

We developed another formula for the sample quality and risk assessment using $|\Delta \mathrm{Tm}|\left(\sigma_{|\Delta \mathrm{Tm}|}\right)$, based on Equation 1. The threshold value of $|\Delta \mathrm{Tm}|$ was estimated to be 0.02 by the standard deviation of Tm among volunteer's GAPDH results. And we adjusted the steepness to give probabilities of 0.05 at CT $0.2+0.1$ and 0.95 at CT 0.2-0.1;

$$
\sigma_{|\Delta \mathrm{Tm}|}(|\Delta \mathrm{Tm}|, 30,0.2)=\frac{1}{1+\mathrm{e}^{30(|\Delta \mathrm{Tm}|-0.2)}} \quad \text { (Equation 3). }
$$

The graphical representation of $\sigma_{|\Delta \mathrm{Tm}|}$ is shown in Fig. 8B.

We combined Equation 2 and Equation 3 into one formula, for SARS-CoV-2 infection risk ( $\left.\sigma_{\text {CovID19 }}\right)$ probability assessment. Since $\sigma_{\mathrm{CT}}$ and $\sigma_{|\Delta \mathrm{Tm}|}$ are independent variables, we multiplied the two components:

$$
\begin{aligned}
\sigma_{\text {Covid19 }}(\mathrm{CT},|\Delta \mathrm{Tm}|)= & \sigma_{\mathrm{CT}} \times \sigma_{|\Delta \mathrm{Tm}|}=\frac{1}{1+\mathrm{e}^{3}(\mathrm{CT}-35)} \\
& \times \frac{1}{1+\mathrm{e}^{30(|\Delta \mathrm{Tm}|-0.2)}} \quad \text { (Equation 4). }
\end{aligned}
$$

After obtaining the probability value, $\sigma_{\text {COVID19 }}$ for each target gene for SARS-CoV-2, we selected the maximum value among the four genes as the final representative risk probability, $\sigma_{\text {CovID19 }}$ for each volunteer sample.

In case of the sampling quality assessment $\left(\sigma_{\text {Quality }}\right)$, only GAPDH was considered and we modified Equation 2 and 4. Since SARSCoV-2 positive control RNA was originated from the Vero cell line, which shows a different Tm compared to human GAPDH, we corrected the $\Delta \mathrm{Tm}$ with a correction factor of 1.05 :

$$
\begin{gathered}
\sigma_{\text {Quality }}\left(\mathrm{CT}_{\mathrm{GAPDH}},|\Delta \mathrm{Tm}|_{\mathrm{GAPDH}}\right)= \\
\sigma_{\mathrm{CT}_{G A P D H}} \times \sigma_{|\Delta \mathrm{Tm}|_{\text {GAPDH }}}= \\
\frac{1}{1+\mathrm{e}^{3\left(\mathrm{CT}_{G A P D H^{-35}}\right)}} \times \frac{1}{1+\left.\mathrm{e}^{30(|| \Delta \mathrm{Tm} \mid-1.05}\right|_{\left.G A P D H^{-0.5}\right)}}
\end{gathered}
$$

(Equation 5).

The correction factor of 1.05 for $\Delta \mathrm{Tm}$ of Vero cell GAPDH 
A

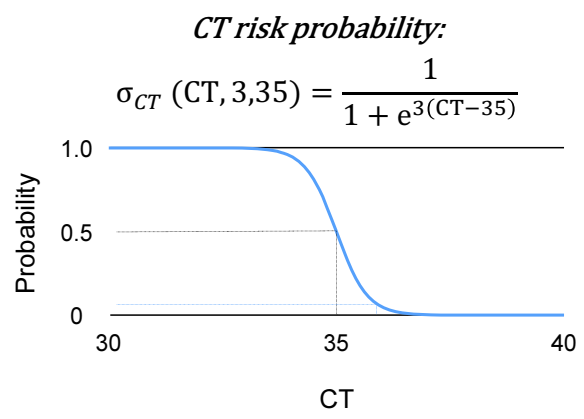

C

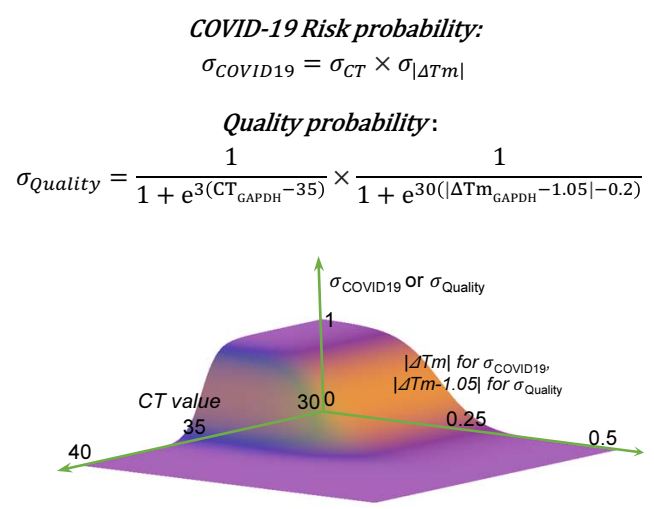

B $\quad / \Delta T m /$ Risk probability:

$$
\sigma_{|\Delta T m|}(|\Delta \mathrm{Tm}|, 30,0.2)=\frac{1}{1+\mathrm{e}^{30(|\Delta T m|-0.2)}}
$$

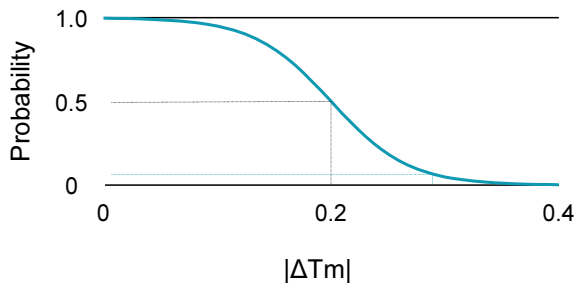

D

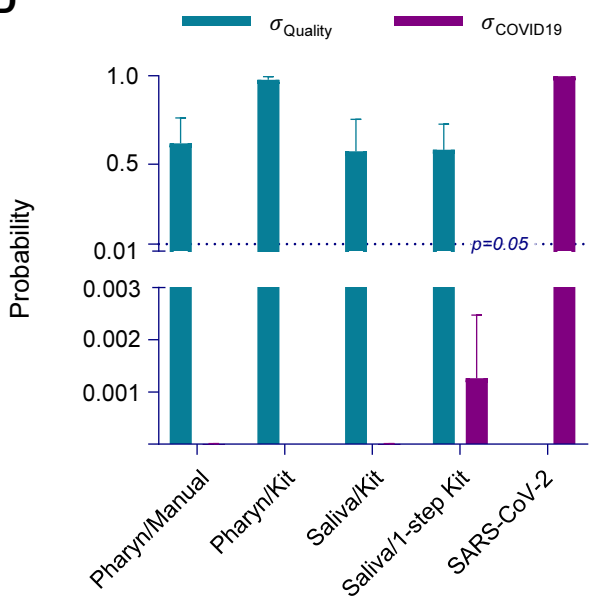

E

Automatic COVID-19 risk assessment

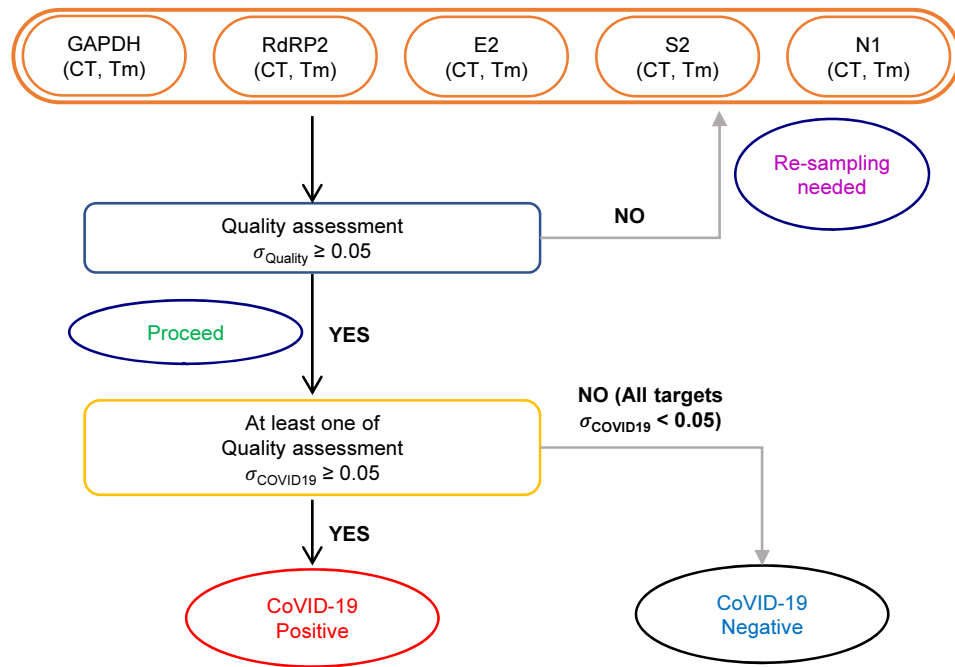

Fig. 8. Risk probability and sampling quality assessment from CT value and $\Delta \mathrm{Tm}$. (A) CT risk probability formula $\left(\sigma_{C T}\right)$ and probability graph for CT value. Dash line represent 0.5 probability at CT 35 (black), and 0.05 probability at CT 36 (blue). (B) Tm risk probability formula ( $\left.\sigma_{|\Delta T \mathrm{~m}|}\right)$ and probability graph for $|\Delta \mathrm{Tm}|$. Dash line represent 0.05 probability at 0.5 probability at $0.2|\Delta \mathrm{Tm}|$ (black), and $0.3|\Delta \mathrm{Tm}|$ (green). (C) SARS-CoV-2 risk probability formula $\left(\sigma_{\text {COVID19 }}\right)$, quality probability formula $\left(\sigma_{\text {Quality }}\right)$ and probability graph for $\sigma_{\text {COVID19, }}$, and $\sigma_{\text {Quality }}$ (D) Summary bar graph for $\sigma_{\text {Quality }}$ (green) and $\sigma_{\text {COVID19 }}$ (purple) for Pharyn/Manual, Pharyn/Kit, Saliva/Kit, Saliva/1-step Kit, and SARS-CoV-2 positive controls. $\sigma_{\text {Quality }}$ in SARS-CoV-2 is not included. Dotted line indicates $\mathrm{p}=0.05$. Data are represented as the mean \pm S.E.M. (E) Flow chart for automatic SARS-CoV-2 risk assessment process. 
Table 3. Sampling quality assessment from $\sigma_{\text {Quality }}$ using internal positive control (GAPDH)

\begin{tabular}{|c|c|c|c|c|c|c|c|c|c|c|}
\hline $\begin{array}{c}\text { Quality assess- } \\
\text { ment }\end{array}$ & $\begin{array}{l}\text { Target/as- } \\
\text { sessment }\end{array}$ & $\begin{array}{l}\text { SARS- } \\
\text { CoV-2 }\end{array}$ & $\begin{array}{c}\text { Volunteer } \\
\text { A }\end{array}$ & $\begin{array}{c}\text { Volunteer } \\
\text { B }\end{array}$ & $\begin{array}{c}\text { Volunteer } \\
\text { C }\end{array}$ & $\begin{array}{c}\text { Volunteer } \\
\text { D }\end{array}$ & $\begin{array}{c}\text { Volunteer } \\
\text { E }\end{array}$ & $\begin{array}{c}\text { Volunteer } \\
\text { F }\end{array}$ & $\begin{array}{c}\text { Volunteer } \\
\text { G }\end{array}$ & NTC \\
\hline Pharyn/Manual & $\begin{array}{l}\text { GAPDH } \\
\text { Assessment }\end{array}$ & $\begin{array}{c}0.998 \\
\text { Proceed }\end{array}$ & $\begin{array}{c}0.799 \\
\text { Proceed }\end{array}$ & $\begin{array}{c}0.039 \\
\text { Re-sam- } \\
\text { pling }\end{array}$ & $\begin{array}{c}0.997 \\
\text { Proceed }\end{array}$ & $\begin{array}{c}0.822 \\
\text { Proceed }\end{array}$ & $\begin{array}{c}0.997 \\
\text { Proceed }\end{array}$ & $\begin{array}{c}0.334 \\
\text { Proceed }\end{array}$ & $\begin{array}{c}0.334 \\
\text { Proceed }\end{array}$ & 0.000 \\
\hline Pharyn/Kit & $\begin{array}{l}\text { GAPDH } \\
\text { Assessment }\end{array}$ & $\begin{array}{c}0.998 \\
\text { Proceed }\end{array}$ & $\begin{array}{c}0.995 \\
\text { Proceed }\end{array}$ & $\begin{array}{c}0.995 \\
\text { Proceed }\end{array}$ & $\begin{array}{c}0.894 \\
\text { Proceed }\end{array}$ & $\begin{array}{c}0.996 \\
\text { Proceed }\end{array}$ & $\begin{array}{c}0.996 \\
\text { Proceed }\end{array}$ & $\begin{array}{c}0.993 \\
\text { Proceed }\end{array}$ & $\begin{array}{l}- \\
-\end{array}$ & 0.000 \\
\hline Saliva/Kit & $\begin{array}{l}\text { GAPDH } \\
\text { Assessment }\end{array}$ & $\begin{array}{c}0.998 \\
\text { Proceed }\end{array}$ & $\begin{array}{c}0.995 \\
\text { Proceed }\end{array}$ & $\begin{array}{c}0.079 \\
\text { Proceed }\end{array}$ & $\begin{array}{c}0.060 \\
\text { Proceed }\end{array}$ & $\begin{array}{c}0.996 \\
\text { Proceed }\end{array}$ & $\begin{array}{c}0.989 \\
\text { Proceed }\end{array}$ & $\begin{array}{c}0.060 \\
\text { Proceed }\end{array}$ & $\begin{array}{c}0.839 \\
\text { Proceed }\end{array}$ & 0.000 \\
\hline Saliva/1-step Kit & $\begin{array}{l}\text { GAPDH } \\
\text { Assessment }\end{array}$ & $\begin{array}{c}1.000 \\
\text { Proceed }\end{array}$ & $\begin{array}{c}0.749 \\
\text { Proceed }\end{array}$ & $\begin{array}{c}0.843 \\
\text { Proceed }\end{array}$ & $\begin{array}{c}0.821 \\
\text { Proceed }\end{array}$ & $\begin{array}{c}0.804 \\
\text { Proceed }\end{array}$ & $\begin{array}{c}0.759 \\
\text { Proceed }\end{array}$ & $\begin{array}{c}0.820 \\
\text { Proceed }\end{array}$ & $\begin{array}{c}0.048 \\
\text { Re-sam- } \\
\text { pling }\end{array}$ & 0.000 \\
\hline
\end{tabular}

should be taken out in case of the positive control originated from the human samples. The graphical representation of $\sigma_{\text {COvID19 }}$ and $\sigma_{\text {Quality }}$ is shown in Fig. 8C.

Based on those equations, we devised an automatic assessment algorithm, starting with the CT and Tm values for each volunteer sample (Fig. 8E). We generated an Excel worksheet (Supplementary Data 1) composed of input cells for CT and Tm values for each target gene of a volunteer sample. Once the CT and Tm values are entered, the embedded formulae automatically calculate $\sigma$ Quality to assess "Re-sampling needed" or "Proceed" and $\sigma_{\text {COVID19 }}$ to assess "COVID-19 Positive" or "COVID-19 Negative."

To automatically assess the sampling quality, $\sigma_{\text {Quality }}$ was calculated from the CT and Tm values of GAPDH qRT-PCR results from Volunteer A through G (Table 3). For the undetermined CT values (u.d.), each CT value was set to 40 , which is the maximum cycle number in qRT-PCR. We found that the volunteer samples in Pharyn/Manual, Pharyn/Kit, Saliva/Kit, and Saliva/1-step Kit showed $\sigma_{\text {Quality }}>0.05$, except 2 cases, indicating that the sampling quality was adequate to "proceed" for further analysis and that there is no need for re-sampling (Table 3). We asked for the resampling from volunteers who had showed $\sigma_{\text {Quality }}<0.05$ in assessment. Notably, the mean $\sigma_{\text {Quality }}$ was well above 0.5 in all procedure groups (Fig. 8D).

After confirming the sampling quality, each qRT-PCR set was further processed for the risk assessment of COVID-19 by automatically calculating $\sigma_{\text {CT }}$ (Table 4$), \sigma_{|\Delta \mathrm{Tm}|}\left(\right.$ Table 5), and $\sigma_{\text {Covid19 }}$ (Table 6). We found that many samples showed $\sigma_{\mathrm{CT}}>0.05$ : ten in Pharyn/Manual, eleven in Pharyn/Kit, six in Saliva/Kit, and fourteen in Saliva/1-step Kit (Table 4), likely caused by CT $<35$. In contrast, most samples showed $\sigma_{|\Delta \mathrm{Tm}|}<0.05$, except for only one in Pharyn/Manual, one in Pharyn/Kit, two in Saliva/Kit, and one in Saliva/1-step Kit showed $\sigma_{|\Delta \mathrm{Tm}|}>0.05$ (Table 5). Finally, none showed $\sigma_{\text {COVID } 19}>0.05$, indicating that all volunteers were "negative" for COVID-18 (Table 6), while the mean $\sigma_{\text {CovID19 }}$ was 0.9975 for
SARS-CoV-2 positive control (Table 6, Fig. 8D). Taken together, the automatic calculation of $\sigma_{\text {Quality }} \sigma_{\mathrm{CT}}, \sigma_{|\Delta \mathrm{Tm}|}$, and $\sigma_{\text {COVID19, }}$, based on CT and Tm values, allowed fast, unsupervised and unbiased assessment of sampling quality and risk of COVID-19.

\section{Application of automatic determination of sampling quality and risk assessment from COVID-19-positive and -negative subjects with Saliva/Kit}

As a proof-of-concept experiment, we tested Saliva/Kit from one SARS-CoV-2-positive and one SARS-CoV-2-negative subjects in the clinic (Fig. 9). We found that SARS-CoV-2 genes and GAPDH were detected in SARS-CoV-2-positive subject, although only GAPDH was detected in SARS-CoV-2-negative subject (Fig. 9A E). SARS-CoV-2 positive subject showed 26.5 to $33.5 \mathrm{CT}$ value for SARS-CoV-2 detection (Fig. 9F). Based on our estimation of the protocol efficiency in previous study [9], we estimated that 10 100 viral copies per each qRT-PCR reaction were present in the self-saliva sample. For automatic determination of sampling quality and risk assessment, we entered CT value and Tm value for each test in the Automatic COVID-19 risk assessment sheet in Supplementary Data 1 (Fig. 9F). We adjustmed GAPDH CT correction value from 1.05 to 0.5 to correct for the different qRTPCR machine what we used. This sheet automatically determined COVID-19-positive or -negative, which accurately corresponded to the clinical diagnosis. Therefore, we validated that our Saliva/ Kit sampling method, SARS-CoV-2 detection protocol, and COVID-19 risk assessment algorithm work properly in clinical settings.

\section{DISCUSSION}

In this study we have extended our previous studies on development of laboratory-safe detection protocol using pharyngeal swab sampling method and further optimization of primer sets for SARS-CoV-2 and internal positive control (GAPDH) to develop 
Table 4. SARS-CoV-2 infection risk assessment from $\sigma_{\mathrm{CT}}$

\begin{tabular}{|c|c|c|c|c|c|c|c|c|c|c|}
\hline Risk probability (CT) & Target & $\begin{array}{l}\text { SARS- } \\
\text { CoV-2 }\end{array}$ & $\begin{array}{l}\text { Volun- } \\
\text { teer A }\end{array}$ & $\begin{array}{l}\text { Volun- } \\
\text { teer B }\end{array}$ & $\begin{array}{l}\text { Volun- } \\
\text { teer C }\end{array}$ & $\begin{array}{l}\text { Volun- } \\
\text { teer D }\end{array}$ & $\begin{array}{l}\text { Volun- } \\
\text { teer E }\end{array}$ & $\begin{array}{l}\text { Volun- } \\
\text { teer F }\end{array}$ & $\begin{array}{l}\text { Volun- } \\
\text { teer G }\end{array}$ & NTC \\
\hline \multirow[t]{4}{*}{ Pharyngeal, Trizol-manual } & RdRP2 & 1.000 & 0.648 & 0.595 & 0.109 & 0.475 & 0.350 & 0.000 & 0.000 & 0.000 \\
\hline & E2 & 1.000 & 0.000 & 0.000 & 0.000 & 0.000 & 0.000 & 0.000 & 0.000 & 0.000 \\
\hline & S2 & 1.000 & 0.000 & 0.003 & 0.061 & 0.007 & 0.002 & 0.007 & 0.000 & 0.012 \\
\hline & N1 & 1.000 & 0.829 & 0.720 & 0.783 & 0.066 & 0.001 & 0.000 & 0.000 & 0.000 \\
\hline \multirow[t]{4}{*}{ Pharyngeal, Trizol-Kit } & RdRP2 & 1.000 & 0.457 & 0.312 & 0.337 & 0.763 & 0.999 & 0.029 & - & 0.350 \\
\hline & E2 & 1.000 & 0.571 & 0.498 & 0.000 & 0.015 & 0.000 & 0.000 & - & 0.053 \\
\hline & S2 & 1.000 & 0.001 & 0.000 & 0.713 & 0.068 & 0.875 & 0.000 & - & 0.000 \\
\hline & N1 & 1.000 & 0.000 & 0.001 & 0.179 & 0.046 & 0.000 & 0.000 & - & 0.008 \\
\hline \multirow{4}{*}{$\begin{array}{l}\text { Saliva, Trizol-Kit, 2-step } \\
\text { qRT-PCR }\end{array}$} & RdRP2 & 1.000 & 0.588 & 1.000 & 0.004 & 0.028 & 0.118 & 0.036 & 0.418 & 0.059 \\
\hline & E2 & 1.000 & 0.000 & 0.179 & 0.000 & 0.000 & 0.000 & 0.000 & 0.001 & 0.000 \\
\hline & S2 & 1.000 & 0.000 & 0.000 & 0.000 & 0.000 & 0.165 & 0.000 & 0.000 & 0.034 \\
\hline & N1 & 1.000 & 0.000 & 0.000 & 0.000 & 0.000 & 0.002 & 0.000 & 0.000 & 0.000 \\
\hline \multirow{4}{*}{$\begin{array}{l}\text { Saliva, Trizol-Kit, 1-step } \\
\text { qRT-PCR }\end{array}$} & RdRP2 & 1.000 & 0.872 & 0.000 & 0.990 & 1.000 & 1.000 & 0.005 & 1.000 & 0.207 \\
\hline & E2 & 1.000 & 0.000 & 0.504 & 0.000 & 0.000 & 0.001 & 0.868 & 0.060 & 0.000 \\
\hline & S2 & 1.000 & 0.000 & 0.256 & 0.000 & 0.000 & 0.002 & 0.000 & 1.000 & 0.000 \\
\hline & N1 & 1.000 & 0.761 & 0.761 & 0.066 & 0.023 & 0.974 & 0.023 & 0.997 & 0.000 \\
\hline
\end{tabular}

Table 5. SARS-CoV-2 infection risk assessment from $\sigma_{|\Delta \mathrm{Tm}|}$

\begin{tabular}{|c|c|c|c|c|c|c|c|c|c|c|}
\hline Risk probability $(|\Delta \mathrm{Tm}|)$ & Target & $\begin{array}{l}\text { SARS- } \\
\text { CoV-2 }\end{array}$ & $\begin{array}{l}\text { Volun- } \\
\text { teer A }\end{array}$ & $\begin{array}{l}\text { Volun- } \\
\text { teer B }\end{array}$ & $\begin{array}{l}\text { Volun- } \\
\text { teer C }\end{array}$ & $\begin{array}{l}\text { Volun- } \\
\text { teer D }\end{array}$ & $\begin{array}{l}\text { Volun- } \\
\text { teer E }\end{array}$ & $\begin{array}{l}\text { Volun- } \\
\text { teer F }\end{array}$ & $\begin{array}{l}\text { Volun- } \\
\text { teer G }\end{array}$ & NTC \\
\hline \multirow[t]{4}{*}{ Pharyngeal, Trizol-manual } & RdRP2 & 0.998 & 0.000 & 0.000 & 0.000 & 0.000 & 0.000 & 0.000 & 0.000 & 0.000 \\
\hline & E2 & 0.998 & 0.000 & 0.705 & 0.000 & 0.000 & 0.000 & 0.000 & 0.000 & 0.000 \\
\hline & S2 & 0.998 & 0.000 & 0.000 & 0.000 & 0.000 & 0.000 & 0.000 & 0.000 & 0.000 \\
\hline & N1 & 0.998 & 0.000 & 0.000 & 0.000 & 0.000 & 0.000 & 0.000 & 0.000 & 0.000 \\
\hline \multirow[t]{4}{*}{ Pharyngeal, Trizol-Kit } & RdRP2 & 0.998 & 0.000 & 0.000 & 0.000 & 0.000 & 0.000 & 0.000 & - & 0.000 \\
\hline & E2 & 0.998 & 0.000 & 0.000 & 0.039 & 0.000 & 0.000 & 0.000 & - & 0.000 \\
\hline & S2 & 0.998 & 0.000 & 0.000 & 0.000 & 0.000 & 0.000 & 0.000 & - & 0.000 \\
\hline & N1 & 0.998 & 0.000 & 0.000 & 0.000 & 0.000 & 0.000 & 0.000 & - & 0.000 \\
\hline \multirow{4}{*}{$\begin{array}{l}\text { Saliva, Trizol-Kit, 2-step } \\
\text { qRT-PCR }\end{array}$} & RdRP2 & 0.998 & 0.000 & 0.000 & 0.000 & 0.000 & 0.000 & 0.000 & 0.000 & 0.000 \\
\hline & E2 & 0.998 & 0.000 & 0.000 & 0.050 & 0.000 & 0.000 & 0.000 & 0.025 & 0.863 \\
\hline & S2 & 0.998 & 0.000 & 0.000 & 0.000 & 0.000 & 0.000 & 0.000 & 0.000 & 0.000 \\
\hline & N1 & 0.998 & 0.000 & 0.000 & 0.000 & 0.000 & 0.073 & 0.000 & 0.000 & 0.000 \\
\hline \multirow{4}{*}{$\begin{array}{l}\text { Saliva, Trizol-Kit, 1-step } \\
\text { qRT-PCR }\end{array}$} & RdRP2 & 0.998 & 0.000 & 0.000 & 0.000 & 0.000 & 0.000 & 0.000 & 0.000 & 0.000 \\
\hline & E2 & 0.998 & 0.000 & 0.000 & 0.000 & 0.000 & 0.000 & 0.000 & 0.000 & 0.000 \\
\hline & S2 & 0.998 & 0.000 & 0.000 & 0.000 & 0.000 & 0.000 & 0.000 & 0.000 & 0.804 \\
\hline & N1 & 0.998 & 0.000 & 0.000 & 0.000 & 0.058 & 0.000 & 0.000 & 0.000 & 0.000 \\
\hline
\end{tabular}

the ultimate detection protocol using saliva-based sampling with automatic assessment of sample quality and risk for COVID-19. The advantages of our protocol over other previously reported protocols include; 1) the saliva-based self-sampling allows complete spatial separation and medical staff or experimenter, eliminating a possibility of cross-infection, 2) the low-cost and fast (less than 2 hour) protocol provides a flexibility of use in the same-day events, such as attendance in face-to-face conference meetings or admission to sports/performance, and 3) the automatic assessment of sampling quality and risk for COVID-19 allows unbiased, unsupervised, objective, and false-positive-free testing, suitable for mass-scale, high-throughput testing facilities.

In some countries, such as the USA and the United Kingdom, the saliva-sampling has been recently approved as a national verified procedure [7,23]. Saliva-based sampling provides an important advantage of complete spatial separation of medical staff and patients. The convenient feature of saliva-sampling procedure also enables shipping-based collection of samples, provided that the subject inactivates the viral particles of SARS-CoV-2 with Proteinase $\mathrm{K}$ at the site of collection before sending out via delivery services. The rest of the procedures of RNA extraction and qRTPCR can be carried out at any Biosafety Level II Grade molecular 
Table 6. SARS-CoV-2 infection risk assessment from $\sigma_{\text {COVID19 }}$

\begin{tabular}{clccccccccc}
\hline \multirow{2}{*}{ Risk probability } & $\begin{array}{c}\text { Target/ } \\
\text { assessment }\end{array}$ & $\begin{array}{c}\text { SARS- } \\
\text { CoV-2 }\end{array}$ & $\begin{array}{c}\text { Volun- } \\
\text { teer A }\end{array}$ & $\begin{array}{c}\text { Volun- } \\
\text { teer B }\end{array}$ & $\begin{array}{c}\text { Volun- } \\
\text { teer C }\end{array}$ & $\begin{array}{c}\text { Volun- } \\
\text { teer D }\end{array}$ & $\begin{array}{c}\text { Volun- } \\
\text { teer E }\end{array}$ & $\begin{array}{c}\text { Volun- } \\
\text { teer F }\end{array}$ & $\begin{array}{c}\text { Volun- } \\
\text { teer G }\end{array}$ & $\begin{array}{c}\text { NTC } \\
\text { Pharyngeal, Trizol-manual }\end{array}$ \\
& RdRP2 & 0.998 & 0.000 & 0.000 & 0.000 & 0.000 & 0.000 & 0.000 & 0.000 & 0.000 \\
& E2 & 0.998 & 0.000 & 0.000 & 0.000 & 0.000 & 0.000 & 0.000 & 0.000 & 0.000 \\
& S2 & 0.998 & 0.000 & 0.000 & 0.000 & 0.000 & 0.000 & 0.000 & 0.000 & 0.000 \\
& N1 & 0.998 & 0.000 & 0.000 & 0.000 & 0.000 & 0.000 & 0.000 & 0.000 & 0.000 \\
& Assessment & Positive & Negative & Negative & Negative & Negative & Negative & Negative & Negative \\
Pharyngeal, Trizol-Kit & RdRP2 & 0.998 & 0.000 & 0.000 & 0.000 & 0.000 & 0.000 & 0.000 & - & 0.000 \\
& E2 & 0.998 & 0.000 & 0.000 & 0.000 & 0.000 & 0.000 & 0.000 & - \\
& S2 & 0.998 & 0.000 & 0.000 & 0.000 & 0.000 & 0.000 & 0.000 & - \\
Saliva, Trizol-Kit,2-step & N1 & 0.998 & 0.000 & 0.000 & 0.000 & 0.000 & 0.000 & 0.000 & - \\
qRT-PCR & Assessment & Positive & Negative & Negative & Negative & Negative & Negative & Negative & 0.000 \\
& E2 & 0.998 & 0.000 & 0.000 & 0.000 & 0.000 & 0.000 & 0.000 & 0.000 & 0.000 \\
& S2 & 0.998 & 0.000 & 0.000 & 0.000 & 0.000 & 0.000 & 0.000 & 0.000 & 0.000 \\
& N1 & 0.998 & 0.000 & 0.000 & 0.000 & 0.000 & 0.000 & 0.000 & 0.000 & 0.000 \\
Saliva, Trizol-Kit, 1-step & 0.998 & 0.000 & 0.000 & 0.000 & 0.000 & 0.000 & 0.000 & 0.000 & 0.000 \\
qRT-PCR & Assessment & Positive & Negative & Negative & Negative & Negative & Negative & Negative & Negative \\
& RdRP2 & 0.998 & 0.000 & 0.000 & 0.000 & 0.000 & 0.000 & 0.000 & 0.000 & 0.000 \\
& E2 & 0.998 & 0.000 & 0.000 & 0.000 & 0.000 & 0.000 & 0.000 & 0.000 & 0.000 \\
& S2 & 0.998 & 0.000 & 0.000 & 0.000 & 0.000 & 0.000 & 0.000 & 0.000 & 0.000 \\
& N1 & 0.998 & 0.000 & 0.034 & 0.000 & 0.001 & 0.000 & 0.000 & 0.000 & 0.000 \\
& Assessment & Positive & Negative & Negative & Negative & Negative & Negative & Negative & Negative & \\
\hline
\end{tabular}

biology laboratories. We have used both Proteinase K and Trizol to inactivate the viral activity to ensure the complete inactivation. However, there are numerous reports using Protein $\mathrm{K}$ alone to inactivate SARS-CoV-2 [20,24]. If Proteinase $\mathrm{K}$ alone is sufficient to inactivate the viral activity, then it should be used instead of Trizol because Trizol is known for its toxicity [25]. Future experiments are needed to confirm this key feature of Proteinase K to inactivate SARS-CoV-2.

Another advantage of using Proteinase $\mathrm{K}$ alone is that it allows detection of SARS-CoV-2 without RNA extraction [26, 27], which should further reduce the total procedure time to less than one hour. Although we have not tested this possibility, it needs future investigation. Taken together, our study suggests that self-saliva sampling is a reliable method to replace pharyngeal swab for SARS-CoV-2 detection protocol.

During the assessment of sampling quality, we used the correctional factor of 1.05 for the positive control obtained from the Vero cell line originated from the African green monkey $[9,18]$. This correctional factor was necessary because the Tm value for GAPDH-targeted qRT-PCR showed an average deviation of $1.05^{\circ} \mathrm{C}$ between SARS-CoV-2 positive control and volunteer samples (Fig. $3 \mathrm{~F}, 4 \mathrm{~F}, 5 \mathrm{~F}$, and $6 \mathrm{~F}$ ). It is critical to remember that in case of positive controls obtained directly from human patients, this correctional factor should be taken out from the formula.

In addition to our focus on the sampling method, we have focused on developing the ways to minimize the occurrence of a false-positive. To do this, we considered both CT and Tm values of the qRT-PCR results. In most of the currently available commercial detection kits, only the threshold of CT value is used as a basis for "positive" versus "negative". However, we strongly suggest that such protocol imposes a danger of false-positive due to primer-dimerization-mediated amplification, which we have demonstrated that it has a different Tm value from the positive control [18]. To prevent this possibility, we developed the formulae for automatic risk assessment, which reflects both CT and Tm values. This formula utilizes the popular logistic classification model, which is a regression technique that can be performed when the dependent variable is to be bisected. We did not choose a two-dimensional logistic classification model because CT and Tm are independent variables. Instead, we multiplied the two probability functions for CT and Tm to obtain the combined risk probability for each targeted gene (Equation 4). The results of the automatic calculation and evaluation show that all of the volunteer samples have expected "negative" assessment. These promising results show the high potential and usefulness our model and formulae in largescale testing.

We conducted this study only with one COVID-19 positive subject. Further research with more COVID-19 patients at a largescale may provide more clinically optimized protocol. 


\section{Saliva/Kit, Human Subjects}

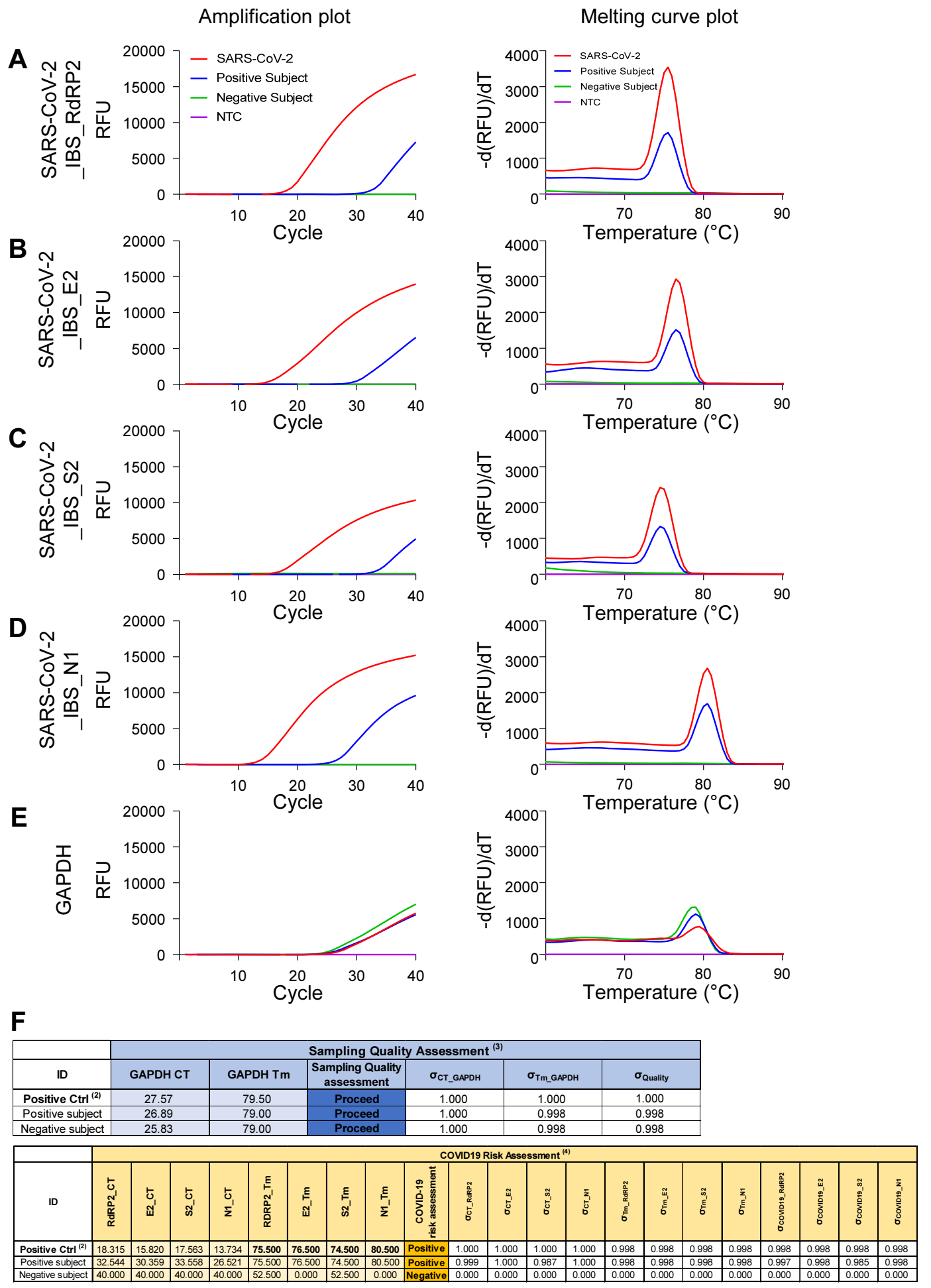

Fig. 9. Amplification and melting curve plot from Human Subject's Saliva/Kit samples. Amplification plot (left panel) and melting curve plot (right panel) from qRT-PCR of human subjects saliva/Kit samples. To determine whether volunteers are infected to SARS-CoV-2, qRT-PCR was performed by using the previously reported SARS-CoV-2 primer sets; (A) SARS-CoV-2_IBS_RdRP2, (B) SARS-CoV-2_IBS_E2, (C) SARS-CoV-2_IBS_S2, (D) SARS-CoV-2_IBS_N1. (E) GAPDH primer set was used for IPC detection. Each color code represent individual subject result and SARS-CoV-2 amplification was represent as red color. (F) Sampling quality assessment and COVID-19 risk assessment with Automatic COVID-19 risk assessment in Supplementary Data 1. 


\section{ACKNOWLEDGEMENTS}

This work was supported by financial support by Institute for Basic Science, Center for Cognition and Sociality (IBS-R001-D2) to C.J.L.

\section{REFERENCES}

1. Jiang F, Deng L, Zhang L, Cai Y, Cheung CW, Xia Z (2020) Review of the clinical characteristics of coronavirus disease 2019 (COVID-19). J Gen Intern Med 35:1545-1549.

2. Gao Z, Xu Y, Sun C, Wang X, Guo Y, Qiu S, Ma K (2020) A systematic review of asymptomatic infections with COVID-19. J Microbiol Immunol Infect. doi: 10.1016/j.jmii.2020.05.001.

3. Ou X, Liu Y, Lei X, Li P, Mi D, Ren L, Guo L, Guo R, Chen T, Hu J, Xiang Z, Mu Z, Chen X, Chen J, Hu K, Jin Q, Wang J, Qian Z (2020) Characterization of spike glycoprotein of SARS-CoV-2 on virus entry and its immune cross-reactivity with SARS-CoV.Nat Commun 11:1620.

4. World Health Organization (2020) WHO coronavirus disease (COVID-19) dashboard [Internet]. World Health Organization, Geneva. Available from: https://covid19.who. int/?gclid=CjwKCAjwlID8BRAFEiwAnUoK1TvTluMRgHP rdYhLgrLexxW2npVTCJ4nfhfTPDuvf-L9iESDW6joqRoCW1AQAvD_BwE.

5. Williamson EJ, Walker AJ, Bhaskaran K, Bacon S, Bates C, Morton CE, Curtis HJ, Mehrkar A, Evans D, Inglesby P, Cockburn J, McDonald HI, MacKenna B, Tomlinson L, Douglas IJ, Rentsch CT, Mathur R, Wong AYS, Grieve R, Harrison D, Forbes H, Schultze A, Croker R, Parry J, Hester F, Harper S, Perera R, Evans SJW, Smeeth L, Goldacre B (2020) Factors associated with COVID-19-related death using OpenSAFELY. Nature 584:430-436.

6. Corman VM, Landt O, Kaiser M, Molenkamp R, Meijer A, Chu DK, Bleicker T, Brünink S, Schneider J, Schmidt ML, Mulders DG, Haagmans BL, van der Veer B, van den Brink S, Wijsman L, Goderski G, Romette JL, Ellis J, Zambon M, Peiris M, Goossens H, Reusken C, Koopmans MP, Drosten C (2020) Detection of 2019 novel coronavirus (2019-nCoV) by realtime RT-PCR. Euro Surveill 25:2000045.

7. World Health Organization (2020) Diagnostic testing for SARS-CoV-2 [Internet]. World Health Organization, Geneva. Available from: https://www.who.int/publications/i/item/ diagnostic-testing-for-sars-cov-2.

8. Marty FM, Chen K, Verrill KA (2020) How to obtain a nasopharyngeal swab specimen. N Engl J Med 382:e76.

9. Won J, Lee S, Park M, Kim TY, Park MG, Choi BY, Kim D,
Chang H, Kim VN, Lee CJ (2020) Development of a laboratory-safe and low-cost detection protocol for SARS-CoV-2 of the coronavirus disease 2019 (COVID-19). Exp Neurobiol 29:107-119.

10. Malecki M, Lüsebrink J, Teves S, Wendel AF (2020) Pharynx gargle samples are suitable for SARS-CoV-2 diagnostic use and save personal protective equipment and swabs. Infect Control Hosp Epidemiol. doi: 10.1017/ice.2020.229.

11. Nguyen LH, Drew DA, Graham MS, Joshi AD, Guo CG, Ma W, Mehta RS, Warner ET, Sikavi DR, Lo CH, Kwon S, Song M, Mucci LA, Stampfer MJ, Willett WC, Eliassen AH, Hart JE, Chavarro JE, Rich-Edwards JW, Davies R, Capdevila J, Lee KA, Lochlainn MN, Varsavsky T, Sudre CH, Cardoso MJ, Wolf J, Spector TD, Ourselin S, Steves CJ, Chan AT; COronavirus Pandemic Epidemiology Consortium (2020) Risk of COVID-19 among front-line health-care workers and the general community: a prospective cohort study. Lancet Public Health 5:e475-e483.

12. Pasomsub E, Watcharananan SP, Boonyawat K, Janchompoo $\mathrm{P}$, Wongtabtim G, Suksuwan W, Sungkanuparph S, Phuphuakrat A (2020) Saliva sample as a non-invasive specimen for the diagnosis of coronavirus disease 2019: a cross-sectional study. Clin Microbiol Infect. doi: S1 198-743X(20)30278-0.

13. Wyllie AL, Fournier J, Casanovas-Massana A, Campbell M, Tokuyama M, Vijayakumar P, Geng B, Muenker MC, Moore AJ, Vogels CBF, Petrone ME, Ott IM, Lu P, Venkataraman A, Lu-Culligan A, Klein J, Earnest R, Simonov M, Datta R, Handoko R, Naushad N, Sewanan LR, Valdez J, White EB, Lapidus S, Kalinich CC, Jiang X, Kim DJ, Kudo E, Linehan M, Mao T, Moriyama M, Oh JE, Park A, Silva J, Song E, Takahashi T, Taura M, Weizman OE, Wong P, Yang Y, Bermejo S, Odio C, Omer SB, Dela Cruz CS, Farhadian S, Martinello RA, Iwasaki A, Grubaugh ND, Ko AI (2020) Saliva is more sensitive for SARS-CoV-2 detection in COVID-19 patients than nasopharyngeal swabs. medRxiv. doi: 10.1101/2020.04.16.20067835.

14. Yoon JG, Yoon J, Song JY, Yoon SY, Lim CS, Seong H, Noh JY, Cheong HJ, Kim WJ (2020) Clinical significance of a high SARS-CoV-2 viral load in the saliva. J Korean Med 35:e195.

15. Iwasaki S, Fujisawa S, Nakakubo S, Kamada K, Yamashita Y, Fukumoto T, Sato K, Oguri S, Taki K, Senjo H, Sugita J, Hayasaka K, Konno S, Nishida M, Teshima T (2020) Comparison of SARS-CoV-2 detection in nasopharyngeal swab and saliva. J Infect 81:e145-e147.

16. Sakanashi D, Asai N, Nakamura A, Miyazaki N, Kawamoto Y, Ohno T, Yamada A, Koita I, Suematsu H, Hagihara M, Shiota A, Kurumiya A, Sakata M, Kato S, Muramatsu Y, Koizumi Y, Kishino T, Ohashi W, Yamagishi Y, Mikamo H (2021) 
Comparative evaluation of nasopharyngeal swab and saliva specimens for the molecular detection of SARS-CoV-2 RNA in Japanese patients with COVID-19. J Infect Chemother 27:126-129.

17. Kim SE, Lee JY, Lee A, Kim S, Park KH, Jung SI, Kang SJ, Oh TH, Kim UJ, Lee SY, Kee SJ, Jang HC (2020) Viral load kinetics of SARS-CoV-2 infection in saliva in Korean patients: a prospective multi-center comparative study. J Korean Med Sci 35:e287.

18. Park M, Won J, Choi BY, Lee CJ (2020) Optimization of primer sets and detection protocols for SARS-CoV-2 of coronavirus disease 2019 (COVID-19) using PCR and real-time PCR. Exp Mol Med 52:963-977.

19. Kim D, Lee JY, Yang JS, Kim JW, Kim VN, Chang H (2020) The architecture of SARS-CoV-2 transcriptome. Cell 181:914-921.e10.

20. Sentmanat M, Kouranova E, Cui X (2020) One-step RNA extraction for RT-qPCR detection of 2019-nCoV. bioRxiv. doi: 10.1101/2020.04.02.022384.

21. Chu DKW, Pan Y, Cheng SMS, Hui KPY, Krishnan P, Liu Y, Ng DYM, Wan CKC, Yang P, Wang Q, Peiris M, Poon LLM (2020) Molecular diagnosis of a novel coronavirus (2019-nCoV) causing an outbreak of pneumonia. Clin Chem 66:549-555.

22. Tolles J, Meurer WJ (2016) Logistic regression: relating patient characteristics to outcomes. JAMA 316:533-534.
23. Department of Health and Social Care (2020) National technical validation process for manufacturers of SARS-CoV-2 (COVID-19) tests [Internet]. Department of Health and Social Care, London. Available from: https://www.gov.uk/ government/publications/assessment-and-procurement-ofcoronavirus-covid-19-tests/coronavirus-covid-19-serologyand-viral-detection-testing-uk-procurement-overview.

24. Chu AW, Chan WM, Ip JD, Yip CC, Chan JF, Yuen KY, To KK (2020) Evaluation of simple nucleic acid extraction methods for the detection of SARS-CoV-2 in nasopharyngeal and saliva specimens during global shortage of extraction kits. J Clin Virol 129:104519.

25. Blow JA, Dohm DJ, Negley DL, Mores CN (2004) Virus inactivation by nucleic acid extraction reagents. J Virol Methods 119:195-198.

26. Lübke N, Senff T, Scherger S, Hauka S, Andrée M, Adams O, Timm J, Walker A (2020) Extraction-free SARS-CoV-2 detection by rapid RT-qPCR universal for all primary respiratory materials. J Clin Virol 130:104579.

27. Lalli MA, Langmade SJ, Chen X, Fronick CC, Sawyer CS, Burcea LC, Wilkinson MN, Fulton RS, Heinz M, Buchser WJ, Head RD, Mitra RD, Milbrandt J (2020) Rapid and extraction-free detection of SARS-CoV-2 from saliva by colorimetric reverse-transcription loop-mediated isothermal amplification. Clin Chem. doi: 10.1093/clinchem/hvaa267. 